\title{
Phosphorylation of Focal Adhesion Kinase at Tyr925: Role in Glia-Dependent and Independent Migration Through Regulating Cofilin and N- Cadherin
}

\author{
Lingzhen Song \\ Center for Molecular Neurobilogy, University Medical Center Hamburg-Eppendorf \\ https://orcid.org/0000-0001-8768-1256
}

\section{Shanting Zhao}

College of Veterinary Medicine, Northwest A\&F University

\section{Michael Frotscher}

Universitatsklinikum Hamburg-Eppendorf

Xuejun Chai ( $\nabla$ xchai@xiyi.edu.cn )

College of Basic Medicine, Xi'an Medical University https://orcid.org/0000-0002-5590-4328

\section{Research Article}

Keywords: Focal adhesion kinase, locomotion, translocation, Reelin, Cofilin, N-Cadherin

Posted Date: November 15th, 2021

DOI: https://doi.org/10.21203/rs.3.rs-1058354/v1

License: (c) (i) This work is licensed under a Creative Commons Attribution 4.0 International License.

Read Full License 


\section{Abstract}

The adult neocortex is a six-layered structure, consisting of nearly continuous layers of neurons that are generated with large temporal diversity. During development, cortical neurons originating from the ventricular zone migrate towards the Reelin-containing marginal zone in an inside-out arrangement. Focal adhesion kinase (FAK), one tyrosine kinase localizing to focal adhesions, has been shown to be activated by $\mathrm{Src}$, an important downstream molecule of Reelin signaling, at tyrosine 925 (Y925). Up to date, the precise molecular mechanisms of FAK and its phosphorylation at Y925 during neuronal migration are still unclear. Combining in utero electroporation with immunohistochemistry and live imaging, we examined the function of FAK in regulating neuronal migration. We show that phosphorylated FAK is colocalized with Reelin positive cells in the developing neocortex and hippocampus. Phosphorylation of FAK at Y925 is significantly reduced in reeler mice. Overexpression and dephosphorylation of FAK impair locomotion and translocation, resulting in migration inhibition and dislocation of both late-born and early-born neurons. These migration defects are highly correlated to the function of FAK in regulating cofilin phosphorylation and N-Cadherin expression, both are involved in Reelin signaling pathway. Thus, phosphorylation of focal adhesion kinase at Y925 is crucial for both glia-dependent and independent neuronal migration.

\section{Highlight}

1. FAK and phosphorylation of FAK at Y925 are required for the migration of both early-born and lateborn neurons.

2. FAK is crucial for regulating migratory speed and soma translocation.

3. The function of FAK in neuronal migration is mediated via cofilin and $\mathrm{N}$-Cadherin, which are related to Reelin signaling pathway.

\section{Introduction}

The adult mammalian cerebral cortex consists of six layers that are formed by the precisely coordinated proliferation, migration and lamination of cortical neurons during development, thereby providing a basis for the establishment of functional neuronal connectivity [1]. These neurons originate from radial glia cells in the ventricular zone (VZ) via asymmetric proliferation, migrate towards the pial surface and finally localize their cell bodies in their final destination and form the six aligned layers of the cortical plate (CP) [2-5].

The neurons of layer VI are established first and layers II-V are subsequently formed in an inside-out manner. Two distinct forms of cell movement: locomotion and translocation, are responsible for the migration of cortical neurons [6]. During the early neocortical development, early-born neurons destined to form deep layers migrate in radial glia-independent manner [7], which means they extend leading processes to the superficial marginal zone (MZ) and then shorten their leading processes to lift their cell bodies. This migration model is called somal translocation. Migration of late-born neurons is more 
complex, consisting of multipolar migration, morphology transformation, glia-dependent locomotion and terminal translocation [7-9]. When the leading process of locomoting neurons reaches $M Z$, they switch to terminal translocation mode, in which the somata move rapidly in a radial glia-independent manner [10]. Even though early-born and late-born neurons apply different migrating strategies, precisely regulated adhesion and cytoskeleton dynamics are involved in controlling lamination [11-13]. Impairment in any of these processes has been related to cortical malformation and neurological disorders, which shows lifelong effects on daily life and cognitive function of human beings, as well as of mice [14-17]. Therefore, investigation on the molecular mechanisms underlying cortical lamination, although fairly well established, is still the subject of ongoing refinements.

Among all the known signaling cascades, the Reelin signaling pathway is one of the most studied. Reelin, an extracellular matrix protein, is crucial for controlling layer formation of brain structures, such as the neocortex, hippocampus and cerebellum [18-21]. Reeler mice lacking Reelin expression, mutants deficient in Reelin signaling molecules as well, show severe defects of neuronal migration and layer lamination, as a consequence of which, dampened learning and memory and cognitive and behavioral abnormalities [22-27]. It has been shown that $a_{3} \beta_{1}$ integrins are shown to bind Reelin and control neuronal migration [28]. Moreover, treatment of cortical tissue with Reelin induces phosphorylation of actin depolymerizing protein Cofilin and Src, resulting in stabilization of the actin cytoskeleton [18]. The involvement of Cofilin and Src in Reelin signaling and in neuronal migration is experimental confirmation by our subsequent studies $[29,30]$. Focal adhesion kinase (FAK), one tyrosine kinase localizing to focal adhesions, has been shown to be activated at tyrosine 925 (Y925) by Src [30]. FAK expression is related to cell motility, thus elevated FAK activity in human cancers promotes cell invasion through matrix and tissue barriers [31]. By contrast, FAK-deficient cells have more focal adhesions, spread slower than control cells and respond poorly to multiple cues [32]. It was shown that phosphorylation of FAK by Cdk5 at serine 732 is critical for microtubule organization, nuclear movement and neuronal migration [33]. Consistently, conditional FAK knockdown and ablation in migrating cells display abnormal morphology and defective turnover of Connexins 26, suggesting FAK is required for radial glia-dependent neuronal migration [34]. Recently, impairment of neuronal migration by overexpressing FAK and its mutant was reported during corticogenesis [35].

Despite this wealth of studies, it has remained unclear how FAK and its phosphorylation at Y 925 are involved in neuronal migration and whether the function of FAK is regulated by Reelin. Here, we address these knowledge gaps and investigate the role of FAK in neuronal migration. The present results show that FAK phosphorylation at Y925 is highly related to Reelin in both the neocortex and hippocampus. The migration of both late-born and early-born cortical neurons is inhibited by overexpressing FAK and its dominant-negative mutant. We found that FAK controls the speed of neuronal locomotion within the CP and the final migrating step: terminal translocation and somal translocation of late-born and early-born neurons, respectively. Furthermore, our findings suggest that regulation of these processes by FAK is mediated at the level of actin and cell-cell adhesion, possibly through regulation of activity of cofilin and expression of $\mathrm{N}$-Cadherin through its phosphorylation by Reelin. 


\section{Materials And Methods}

\section{Animals}

All experiments were performed in compliance with the German laws and the guidelines of the European Community for the use of animals in research and were approved by the local ethical committee (48/13). Reeler (B6C3Fe-a/a-Reln ${ }^{\text {rl }}$ ) were obtained from Dr. Joachim Herz (University of Texas Southwestern, Dallas) and bred in University Medical Center Hamburg-Eppendorf animal facility. Timed-pregnant wildtype C57BL/6J mice from the animal facility and reeler mice were housed individually at a $12 \mathrm{~h}$ light/12 $\mathrm{h}$ dark cycle and were given access to water and food ad libitum. The day of vaginal plug detection was considered embryonic day $(E) 0.5$, the day of birth was considered postnatal day $(P) 0$. All experiments were performed on pups of both sexes.

\section{Plasmid construction}

Plasmid pCAG-GFP, a mammalian expression green fluorescent protein (GFP) vector driven by the chicken actin promoter (Addgene, plasmid 11150), was used as a control (CON). pCAG-GFP-FAK (FAK-WT) encoding mouse FAK (GenBank: M95408.1) was constructed by reverse transcription PCR (RT-PCR) and In-Fusion (Takara, Japan). The used primers were designed as follows ( $\mathrm{S}$, sense; $\mathrm{A}$, anti-sense; underlines are the sites of restriction enzyme): (S) 5 '-

GCAAAGAATTGAATTCGCCACCATGGCAGCTGCTTATCTTGACCC-3'; (A)5'-

TGCTCGAGGCAAGCTTGCGTGTGGCCGTGTCTGCCCTAGC-3'. A dominant-negative mutant pCAGFAK(Y925F)-GFP (FAK-DN) mimics the dephosphorylated form by changing tyrosine 925 into phenylalanine was generated by overlap PCR. The mutant primers were designed as follows: (S) 5'GACAAGGTATTTGAGAATGTGAC-3'; (A) 5'-GTCACATTCTCAAATACCTTGTC-3'. Underlines are the sites of the gene mutant. The constructs were further tested by sequence analysis and enzyme restriction. The resulting plasmids were then purified using an Endo-free maxi prep kit from Qiagen.

\section{Cell culture and transfection}

The neuro-2a mouse neuroblastoma cell line (ATCC, CCL-131) were cultured as monolayer cultures in Dulbecco's modified minimal essential medium (DMEM) containing $10 \%(\mathrm{v} / \mathrm{v})$ fetal bovine serum (FBS, Life Technologies), penicillin (100 units/ml) and streptomycin (100 mg/ml; Life Technologies) in a humidified atmosphere containing $95 \%$ air and $5 \% \mathrm{CO}_{2}$ at $37^{\circ} \mathrm{C}$. When used for western blotting, cells were seeded in 60-mm cell/tissue culture dishes $36 \mathrm{~h}$ before transfection. Cells were transfected with liposome (Merck) according to the manufacturer's instructions transfection. For CON and the expression of FAK and its mutant, cells were transfected at a similar dose and transfection conditions.

\section{Western blot analysis}

Total lysates were obtained from 48h transfected neuro-2a cells or the cortex tissue of the brains of P0. Transfected cells were washed with $2 \mathrm{~mL}$ of ice-cold phosphate buffered saline (PBS) and harvested with a cell scraper. For the preparation of brain tissues, hemispheres of newborn pups were isolated in ice-cold 
PBS and the tissues were chopped and resuspended in ice-cold PBS. The harvested cells or tissues were centrifuged at $2300 \mathrm{rpm}$ for 5 min and lysed in RIPA lysis buffer containing $50 \mathrm{mM}$ Tris (pH 7.4), $150 \mathrm{mM}$ $\mathrm{NaCl}, 1 \%$ Triton $\mathrm{X}-100,1 \%$ sodium deoxycholate, $0.1 \%$ SDS, $2 \mathrm{mM} \mathrm{NaF}, 5 \mathrm{mM}$ EDTA and $1 \mathrm{mM}$ sodium orthovanadate. The protease inhibitor phenylmethylsulfonyl fluoride (PMSF, $1 \mathrm{mM}$ ) and phosphatase inhibitor Cocktail-1 (FIVEphoton Biochemicals) were added to the RIPA buffer in advance. After 1-h incubation on ice, the lysates were centrifuged at $10,000 \mathrm{rpm}$ for $10 \mathrm{~min}$ at $4^{\circ} \mathrm{C}$ to remove cell debris. The supernatants were mixed with SDS sample buffer (50 mM Tris- $\mathrm{HCl}(\mathrm{pH} 6.8), 2 \%$ SDS, $10 \%$ glycerol, 100 $\mathrm{mM}$ dithiothreitol, or 5\% 2-mercaptoethanol and bromophenol blue). Protein concentrations were measured and equal amounts were loaded in each condition. The extracted protein was electrophoresed in $12 \%$ SDS-PAGE gels and transferred to $0.45-\mu \mathrm{m}$ polyvinylidene fluoride membranes (PVDF, Millipore). The PVDF membranes were blocked in TBST buffer $(20 \mathrm{mM}$ Tris- $\mathrm{HCl}(\mathrm{pH} 8.0), 150 \mathrm{mM} \mathrm{NaCl}$ and $0.05 \%$ Tween 20) containing 5\% w/v skimmed milk proteins for $3 \mathrm{~h}$ at room temperature (RT) and then incubated with primary antibodies (rabbit polyclonal phospho-FAK (Y925) antibody (1:1000, Cell Signaling Technology), rabbit anti-phospho-cofilin Ser3 (1:1000, Santa Cruz), rabbit anti-Actin (1:5000, Millipore), followed by treatment with horseradish peroxidase (HRP)-conjugated secondary antibodies for $2 \mathrm{~h}$ at RT. After washing three times with TBST, targeted proteins were detected using Enhanced Chemiluminescence (ECL) Plus Western blotting detection reagents (Pierce) according to the manufacturer's instruction. At least three Western blots were analyzed for each experiment. The stained bands were scanned and the relative optical densities were measured for quantization of the relative expression levels of each protein using Fiji analysis software (National Institutes of Health).

\section{In utero electroporation (IUE)}

Timed-pregnant mice (E12.5 or E14.5) were injected subcutaneously with buprenorphine $(0.05 \mathrm{mg} / \mathrm{kg}$ body weight) 30 min before surgery. Surgery was performed on a heating blanket and toe pinch and breathing were monitored throughout. Under isoflurane anesthesia (induction: $5 \%$, maintenance: $3.5 \%$ ), the eyes of the dam were covered with eye ointment to prevent damage before dehairing and disinfecting the abdomen with iodine tincture. A $\sim 3 \mathrm{~cm}$ midline laparotomy was performed and the uterine horns were exposed and moistened with warm sterile phosphate buffered saline (PBS, $\left.37^{\circ} \mathrm{C}, \mathrm{Ph} 7.4\right)$. Solution containing $1.0 \mu \mathrm{g} / \mu \mathrm{l} \mathrm{pCAG-GFP}(\mathrm{CON})$, pCAG-FAK-GFP (FAK-WT) or dominant-negative pCAGFAK(Y925F)-GFP (FAK-DN) and 0.1\% fast green dye at a volume of 0.75-1.25 $\mu \mathrm{l}$ was injected into the right lateral ventricle of individual embryos using pulled borosilicate glass capillaries (GB100TF-10; Science Products, Hofheim, Germany), with a sharp and long tip. Plasmid DNA was purified with NucleoBond (Macherey-Nagel, Germany). IUE was performed as described previously [29, 30,36]. Each embryo within the uterus was placed between the electroporation tweezer-type paddles ( $5 \mathrm{~mm}$ diameter, Protech, TX, USA). Electrode pulses ( $30 \mathrm{~V}, 50 \mathrm{~ms}$ ) were applied six times at intervals of $950 \mathrm{~ms}$ controlled by an electroporator (ECM 830 BTX; Harvard Apparatus). Uterine horns were placed back into the abdominal cavity after electroporation. The abdominal cavity was filled with warm sterile PBS and abdominal muscles and skin were sutured individually with absorbable and non-absorbable suture thread, respectively. After recovery, pregnant mice were returned to their home cages, which were half placed on a heating blanket for two days after surgery and received on a daily basis additional wet food 
supplemented with 2-4 drops Metacam (0.5 mg/ml, Boehringer-Ingelheim, Germany). Dams were sacrificed and the brains of the embryos were used for the preparation of slice cultures (see below). Alternatively, 3,5 , or 7 days after IUE, brains were fixed in $4 \%$ paraformaldehyde (PFA) and sectioned coronally into $50-\mu \mathrm{m}$-thick sections.

\section{Preparation of embryonic cortical slice cultures}

Three days after electroporation, pregnant mice at E17.5 were decapitated under hypothermic anesthesia. The embryos at E17.5 (CON, n=6; FAK-WT, n=6; FAK-DN, n=8) were collected and rapidly placed in ice-cold Hank's balanced salt solution (HBSS; Invitrogen). The brains were dissected from the skull and checked under a fluorescence microscope. GFP-positive cerebral cortices were then dissected and sectioned (300 $\mu \mathrm{m})$ perpendicular to the longitudinal axis of the cerebral cortex using a Mcllwain tissue chopper. The slices were placed onto culture inserts (Millipore) and transferred to 6-well plates with $1 \mathrm{ml} /$ well nutrition medium containing $25 \%$ heat-inactivated horse serum, $25 \%$ Hank's balanced salt solution, $50 \%$ minimal essential medium and $2 \mathrm{mM}$ glutamine ( $\mathrm{pH} \mathrm{7.2;} \mathrm{Invitrogen)} \mathrm{and} \mathrm{incubated} \mathrm{in} 5 \% \mathrm{CO}_{2}$ at $37^{\circ} \mathrm{C}$ for at least 3 h. After recovery, the culture inserts were placed in Petri dishes (30 $\mathrm{mm}$ diameter) with a glass-bottom containing fresh medium and then transferred for live imaging.

\section{Live imaging of slice cultures}

For live imaging of slice cultures, an Improvision confocal spinning-disc microscope (Zeiss) and 20x air immersion objective was used to acquire z-series of cortical slices at $5 \mu \mathrm{m}$ intervals through a tissue depth of about $20 \mu \mathrm{m}$. The z-series were then visualized as single optical scans with concurrent orthogonal views using Volocity 6 software (Perkin Elmer). The time interval was 10 min. Duration of imaging was up to $15 \mathrm{~h}$. This microscope was equipped with a chamber for the control of temperature, humidity and $\mathrm{CO}_{2}$. Results of time-lapse imaging of the slice cultures were analyzed using Volocity 6 software and the average speed of neuronal cell migration was measured by using Imaris software. Measurements from 50 GFP-expressing cells were collected from three videos of each different plasmid transfection and stage ( 3 days after IUE). Only neurons whose migration could be tracked for a substantial distance were included. In these cells, the average speed of movement and the direction of migration (towards the marginal zone or ventricular zone) were measured in the $x$ - and $y$-axes.

\section{Histology and immunohistochemistry and imaging}

Brains were prepared for histological analysis on 3, 5 and 7 days after IUE or from non-treated pregnant dams or newborn pups at the desired date. Pregnant wild-type mice were anesthetized with isoflurane and were decapitated under hypothermic anesthesia and the embryos were dissected in ice-cold HBSS. Five days after IUE, corresponding to the day of birth or seven days after IUE, newborn mice were sacrificed by cervical dislocation under hypothermia and the brains were dissected and rapidly placed in HBSS. Brains after IUE were viewed under a fluorescence microscope to verify transfection. Brains were fixed in $4 \%$ PFA overnight at $4^{\circ} \mathrm{C}$. 
After washing in $0.1 \mathrm{M}$ PBS at RT for several hours, brains were embedded in $5 \%$ agar and cut transversally into 50- $\mu \mathrm{m}$-thick slices on a Leica VT $1000 \mathrm{~S}$ vibratome (Leica Microsystems) and the sections were placed in a 24-well plate containing 0.1 M PBS. For immunohistochemistry, free floating slices were permeabilized and blocked with PBS containing 0.3\% Triton X-100 (Sigma Aldrich), 5\% normal bovine serum albumin (BSA, Jackson ImmunoResearch). Subsequently, slices were incubated overnight with mouse monoclonal anti-Reelin G10 (1:1000, Millipore), rabbit polyclonal anti-phospho-FAK (Y925) (1:1000, Cell Signaling Technology), mouse monoclonal anti-NeuN (1:1000, Millipore) or rabbit monoclonal anti-Brn2 (1:1000, Cell Signaling Technology) diluted in PBS containing $0.03 \%$ Triton X-100, $0.5 \%$ BSA and $1 \%$ normal goat serum (NGS, Sigma), followed by $2 \mathrm{~h}$ incubation with secondary antibody Alexa Fluor-568 goat anti-mouse (1:500, Invitrogen), Alexa Fluor-488 goat anti-rabbit (1:500, Invitrogen), Alexa Fluor-568 donkey anti-mouse (1:500, Invitrogen), Alexa Fluor-647 donkey anti-rabbit (1:500, Invitrogen). DAPI (1:5000) was added to the second antibody for the nuclear labeling. Finally, slices were transferred to glass slides and covered with Vecta-Shield (Vector Laboratories). Sections were photographed using a confocal laser-scanning microscope (Leica TCS SP5) and 20x air or 63× oil immersion objectives. $z$-series of brain sections at $0.5 \mu \mathrm{m}$ intervals through a tissue depth of $9 \mu \mathrm{m}$ were acquired and visualized as single optical scans with concurrent orthogonal views using Leica LAS software (Leica).

\section{Data Analysis}

Of the embryos transfected with the different constructs, at least three brains per different construct and stage were used. Statistical analyses were performed in Graphpad Prism environment. Student's t-tests were used to determine the statistical significance of differences between the two groups. Comparisons among multiple groups were evaluated by one-way analysis of variance (ANOVA) followed by Bonferronicorrected post hoc analysis. Data are presented as mean \pm SEM. Significance levels of $p<0.05\left({ }^{*}, \#\right), p<$ $0.01(\star \star, \#)$ or $p<0.001(\star \star \star, \# \#)$ were used.

\section{Results}

\section{Phosphorylation of FAK at Y925 is related to Reelin expression}

FAK is involved in cell motility through regulating by different molecules and plays a critical role in corticogenesis $[34,33,35]$. However, the function of FAK, especially its phosphorylation of at Y925 (pFAK925) during neuronal migration in vivo and the underlying molecular mechanism is still poorly understood.

To close this knowledge gap, we first performed immunostaining in the developing brain (Fig. 1A, B). pFAK925 was expressed in both neocortex and hippocampal formation at E17.5 (Fig. 1A). p-FAK925 did not show layer preference but was ubiquitously distributed throughout the cortical plate (CP) and subareas of the hippocampus. Exceptions were marginal zone (MZ) of the neocortex, the $M Z$ of the 
dentate gyrus (DG), the prospective outer molecular layer (oml) of the DG, where populate Reelin-positive Cajal-Retzius (CR) cells. Strong p-FAK expression was highly overlapped with Reelin. A similar expression profile was noticed in neocortical and hippocampal slices from P0 mice (Fig. 1B). In addition, we performed Western blots of p-FAK925 in cortical lysates prepared from P0 wild-type mice $\left(\mathrm{rl}^{+/+}\right)$or their reeler ( $\mathrm{rl}^{-/-}$) littermates (Fig. 1C). Densitometric analysis from three independent experiments showed that the protein level of p-FAK925 was significantly downregulated in reeler mutant mice (Fig. 1D, $\left.\mathrm{rl}^{+/+}: 1.00 \pm 0.0, \mathrm{rl}^{-/-}: 0.66 \pm 0.038, \mathrm{p}<0.0001\right)$. Our observations suggest that the function of FAK is highly related to the Reelin signaling pathway during brain development.

\section{FAK disrupts the radial neuronal migration and reduces the migratory speed of late-born neurons}

To further gain insight into the function of FAK during neuronal migration, plasmids overexpressing wildtype FAK (FAK-WT) and a dominant-negative mutant (FAK-DN) by changing tyrosine 925 into phenylalanine were constructed (Fig. 2A). These plasmids were transfected into cultured Neuro-2a cells, exogenous $p$-FAK was detected by immunostaining after $24 \mathrm{~h}$. The elevated phosphorylation of FAK was only seen in the FAK-WT expressing cells but not in GFP (CON) and FAK-DN expressing cells (Fig. 2B). GFP-labelling was found in the whole cell in GFP-transfected control cells, while GFP-labelling was only detected in the cytoplasm and absent in nuclei in cells transfected with plasmids of FAK-WT and FAK-DN. Neuro-2a cells were harvested $48 \mathrm{~h}$ after transfection for Western blot. Strong endogenous p-FAK was found in FAK-WT lysate (Fig. 2C). These results indicate FAK and its mutant were expressed and functioned as expected.

To study the effects of FAK on neuronal migration, in utero electroporation (Tabata and Nakajima, 2003) was employed to overexpress different plasmids in mouse brains at E14.5. Plasmids were transfected into newly generated late-born neurons in the ventricular zone (VZ). After 3 days at E17.5, transfected brains were sectioned. In CON $(n=10)$, numerous GFP-positive cells migrated into both the upper region of the CP (UCP) and the deeper region of the CP (DCP) (Fig. 3A). However, neurons in brains transfected with the plasmid expressing FAK-WT $(n=8)$ and FAK-DN $(n=10)$ had fewer neurons invaded the CP, but more accumulated in the intermediate zone (IZ) and ventricular zone/subventricular zone (VZ/SVZ) (Fig. 3B, Table 1). In CON group, the transfected cells that were migrating in the CP showed a typical bipolarity morphology in vivo (Fig. 3C), which is a long and thick leading process directed toward the pial surface and a short, thin trailing process pointing to the VZ. Similar to Neuro-2a cells in vitro, overexpression of FAK-WT and FAK-DN was mainly located in processes and the perinuclear region of migrating neurons. Moreover, compared to the even distribution of GFP signal in CON neurons, aggregates of FAK-WT and FAK-DN were found in the unsmooth-looking membrane of neurons (Fig. 3C), which might be the sites of focal adhesions between neurons or neurons with glial cells (Fig. 3C). Given the polarity of migrating neurons was barely affected, we checked the migratory behavior of neurons transfected with the different constructs using time-lapse imaging. CON cells revealed their characteristic bipolar shape and moved smoothly by nuclear translocation ( $n=227$ cells, $18.93 \pm 0.646 \mu \mathrm{m} / \mathrm{h}$, Fig. 3D-E, Tabel 1, Movie 1, 2). By 
contrast, neurons transfected with FAK-WT showed slower forward movement ( $\mathrm{n}=256$ cells, $16.14 \pm$ $0.515 \mu \mathrm{m} / \mathrm{h}, \mathrm{p}=0.0025$, Fig. 3D-E, Tabel 1, Movie 3, 4), as well as in FAK-DN neurons ( $\mathrm{n}=338$ cells, $15.92 \pm$ $0.510 \mu \mathrm{m} / \mathrm{h}, \mathrm{p}=0.0004$, Fig. 3D-E, Tabel 1, Movie 5, 6). Thus, overexpression and mutation of FAK disrupt the radial neuronal migration of late-born neurons, at least partially by reducing their migratory speed. Of note, since the plasmids we used were fused FAK with GFP, so GFP represented the distribution changing of FAK during locomotion circles. In FAK-WT transfected neurons, the dynamic GFP signal was observed inside the migrating neurons. FAK-WT either spread relatively more 'even' in the cytoplasm and the leading process (Fig. 3D, FAK-WT, 0-40 min) or aggregated in the perinuclear area of the leading process and tail process (Fig. 3D, FAK-WT, 60-100, 180-200 min) or localized on one side of the cell body (possible the interaction side between neuron and radial glial cell, Fig. 3D, FAK-WT, 120-160 min). In contrast, the FAK-DN transfected cells showed a more stable GFP signal (Fig. 3D, FAK-DN 40-200 min), especially in the FAK-DN high-expressing migrating neuron (Movie 7). 
Table 1

Summary of the distribution pattern, locomotion speed and soma location of cortical neurons in neocortex after IUE.

\begin{tabular}{|c|c|c|c|c|c|}
\hline \multicolumn{2}{|c|}{ Neuronal Distribution } & \multirow{3}{*}{$\begin{array}{l}\text { CON } \\
28.83 \pm \\
3.107\end{array}$} & \multirow{2}{*}{$\begin{array}{l}\text { FAK-WT } \\
17.41 \pm \\
2.821\end{array}$} & \multirow{2}{*}{$\begin{array}{l}\text { FAK-DN } \\
14.07 \pm \\
1.800\end{array}$} & \multirow{3}{*}{$\begin{array}{l}\text { F values } \\
F(2,25)=9.203 \\
P=0.001\end{array}$} \\
\hline \multirow[t]{10}{*}{$\begin{array}{l}\text { E14.5- } \\
\text { E17.5 }\end{array}$} & \multirow[t]{2}{*}{ UCP (\%) } & & & & \\
\hline & & & ${ }^{*} p=0.0179$ & $*^{*} p=0.0011$ & \\
\hline & \multirow[t]{2}{*}{ DCP (\%) } & \multirow[t]{2}{*}{$\begin{array}{l}20.58 \pm \\
1.452\end{array}$} & \multirow{2}{*}{$\begin{array}{l}15.34 \pm \\
1.108 \\
\star_{p}=0.0251\end{array}$} & \multirow[t]{2}{*}{$\begin{array}{l}17.86 \pm \\
1.124\end{array}$} & $F(2,25)=4.113$ \\
\hline & & & & & $P=0.0281$ \\
\hline & \multirow[t]{2}{*}{ IZ (\%) } & \multirow{2}{*}{$\begin{array}{l}31.06 \pm \\
3.693\end{array}$} & \multirow{2}{*}{$\begin{array}{l}40.81 \pm \\
5.914\end{array}$} & \multirow{2}{*}{$\begin{array}{l}33.70 \pm \\
5.811\end{array}$} & $F(2,25)=1.638$ \\
\hline & & & & & $P=0.2146$ \\
\hline & \multirow[t]{2}{*}{ VZ/SVZ (\%) } & \multirow[t]{2}{*}{$\begin{array}{l}19.53 \pm \\
2.135\end{array}$} & \multirow[t]{2}{*}{$\begin{array}{l}27.69 \pm \\
4.295\end{array}$} & \multirow{2}{*}{$\begin{array}{l}34.37 \pm \\
4.378 \\
*_{p}=0.0205\end{array}$} & $F(2,25)=4.358$ \\
\hline & & & & & $P=0.0 \angle 280$ \\
\hline & \multirow[t]{2}{*}{$\begin{array}{l}\text { Locomotion speed } \\
(\mu \mathrm{m} / \mathrm{h})\end{array}$} & \multirow[t]{2}{*}{$\begin{array}{l}18.93 \pm \\
0.646\end{array}$} & $\begin{array}{l}16.14 \pm \\
0.515\end{array}$ & $\begin{array}{l}15.92 \pm \\
0.510\end{array}$ & $F(2,818)=8.401$ \\
\hline & & & $* * p=0.0025$ & $* \star * \mathrm{p}=0.0004$ & -0.0002 \\
\hline \multirow[t]{9}{*}{ E14.5-P0 } & \multirow[t]{3}{*}{ II/III (\%) } & \multirow{3}{*}{$\begin{array}{l}91.02 \pm \\
1.945\end{array}$} & \multirow{3}{*}{$\begin{array}{l}59.39 \pm \\
4.156 \\
\star \star \star p<0.0001\end{array}$} & \multirow{3}{*}{$\begin{array}{l}73.73 \pm \\
1.881 \\
* p=0.0118 \\
\#_{p}=0.0273\end{array}$} & $F(2,16)=23.84$ \\
\hline & & & & & $P<0.0001$ \\
\hline & & & & & \\
\hline & \multirow[t]{2}{*}{ IV (\%) } & \multirow[t]{2}{*}{$\begin{array}{l}4.25 \pm \\
1.246\end{array}$} & $\begin{array}{l}15.60 \pm \\
1.301\end{array}$ & $\begin{array}{l}16.08 \pm \\
1.387\end{array}$ & $F(2,16)=24.33$ \\
\hline & & & $\star \star \star p<0.0001$ & $* * * p<0.0001$ & $r<0.0001$ \\
\hline & \multirow[t]{2}{*}{ V/VI (\%) } & \multirow{2}{*}{$\begin{array}{l}3.24 \pm \\
0.829\end{array}$} & \multirow{2}{*}{$\begin{array}{l}17.57 \pm \\
2.832 \\
\star \star p=0.0014\end{array}$} & $8.38 \pm 2.398$ & $F(2,16)=10.10$ \\
\hline & & & & $p=0.0505$ & $P=0.0015$ \\
\hline & \multirow[t]{2}{*}{ IZ (\%) } & $\begin{array}{l}1.49 \pm \\
0.515\end{array}$ & $\begin{array}{l}7.44 \pm \\
2.201\end{array}$ & $1.81 \pm 0.487$ & $F(2,16)=4.401$ \\
\hline & & & $*_{p}=0.0414$ & & $P=0.030$ \\
\hline
\end{tabular}

Data are shown as mean \pm SEM. Significance was assessed using one-way analysis of variance (ANOVA) test followed by Bonferroni-corrected post hoc test and the listed $p$ values correspond to comparisons between CON and FAK-WT CON and FAK-DN ( $\left.{ }^{\star} \mathrm{p}<0.05,{ }^{\star *} \mathrm{p}<0.01,{ }^{\star * *} \mathrm{p}<0.01\right)$, FAK-WT and FAK-DN $\left({ }^{\#} p<0.05,{ }^{\# \#} p<0.01, \# \# p<0.001\right)$. 


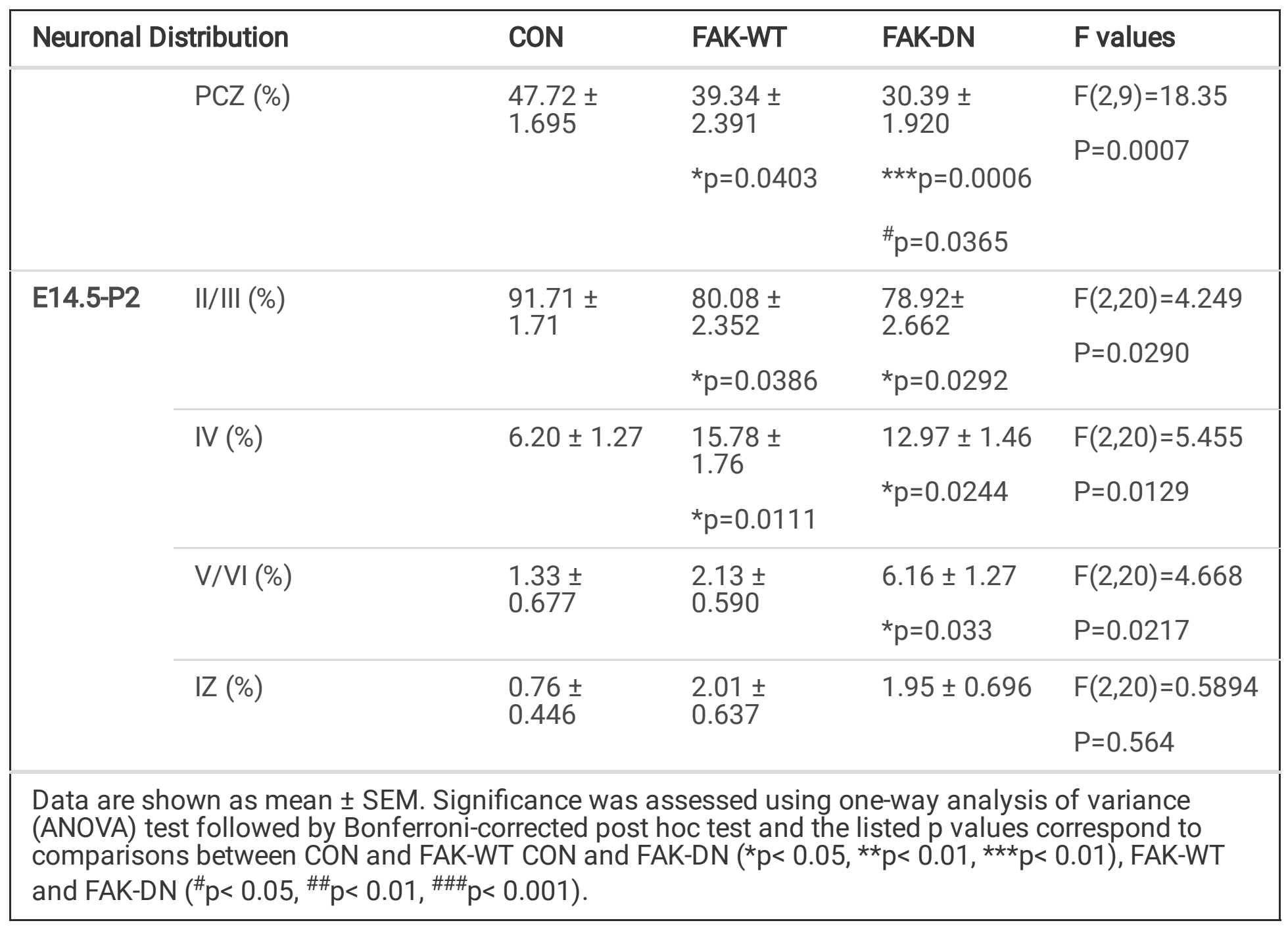

The migration defects observed above led to the question of whether the final location of late-born neurons is affected as well. Next, we examined the transfected brains after birth at P0. At this time point, most neurons have terminated their migration and reached their destinations in the CP. More than $90 \%$ of all labeled CON cells $(n=6,91.02 \pm 1.945 \%)$ formed a compact layer subjacent to the $M Z$, which is layer II/III of the cortex (Fig. 4A, B, Tabel 1). Layer IV, V/VI and IZ contained a few neurons (Fig. 4A, B, Tabel 1). Notably, the distribution pattern of FAK-WT transfected cells was quite different from that in the CON group (Fig. 4A). Significantly fewer cells ( $n=8,59.39 \pm 4.156 \%, p<0.0001)$ were found in the layer II/III of the $\mathrm{CP}$, while significantly more cells in layer IV, V/VI and IZ (Fig. 4B, Tabel 1). The majority of FAK-DN neurons ( $n=5,73.73 \pm 1.881 \%, p=0.0118$ ) occupied layer II/III, whose number was significantly lower than in the CON group. Consequently, there were much more neurons stacked in layer IV (Fig. 4B, Tabel 1). Furthermore, the neurons that reached layer II/III were significantly less $(p=0.0273)$ in the FAK-WT group when compared to the FAK-DN group as well. These migration impairments in the FAK-WT and FAK-DN groups lasted till P2 when there were still much more transfected neurons not reaching their final destination in layer II/III (Fig. 4C, D, CON: $n=4,91.71 \pm 1.71 \%$; FAK-WT: $n=7,80.08 \pm 2.352 \%, p=0.0386$; FAK-DN: $n=12,78.92 \pm 2.662 \%, p=0.0292$, Tabel 1), but more neurons stayed in layer IV and V/VI (Fig. 4C, D, Tabel 1). These mislocated neurons gave rise to several branches (Fig. 4C), suggesting their migration stopped and differentiation started. 
These data indicate that overexpression of FAK and its mutant induces migration defects of late-born neurons, not only delaying the locomotion but the final destination.

FAK is required for glia-independent terminal translocation in late-born neurons and somal translocation in early-born neurons

The abnormal location of FAK-WT and FAK-DN neurons observed above suggests that their migration disturbance was not solely related to the reduction of locomotion speed, but was contributed by other processes regulated by FAK. One possible process might be the glia-independent terminal translocation. Locomoting neurons directionally migrate toward the pia surface and when they arrive beneath $M Z$ they apply their final migration mode, in which they extend processes to the $M Z$ and shorten their leading processes to move their cell bodies to their final positions [10].

To directly test this hypothesis, we then first monitored the effect of FAK-WT and FAK-DN on terminal translocation in late-born neurons. These neurons transiently pause and accumulate, forming into the primitive cortical zone (PCZ). At P0, PCZ could be identified by dual staining of NeuN and Brn2 (Fig. 5A). Quantification showed that, in the CON group, $47.72 \pm 1.695 \%(n=4)$ transfected neurons located their somata in the NeuN ${ }^{-} B r n 2^{+}$PCZ region (Fig. 5A, B), whereas there was a much lower number of neurons in FAK-WT $(n=4,39.34 \pm 2.391 \%, p=0.0403$, Tabel 1$)$ and FAK-DN group $(n=4,30.39 \pm 1.920 \%, p=0.0006$, Tabel 1). Of note, the difference of this number in FAK-WT and FAK-DN was significant as well $(p=0.0365)$. These results suggest that the terminal translocation of late-born neurons was affected by FAK manipulation.

Second, we studied the migration of early-born neurons in the early developmental stages since they undergo somal translocation mode, which is morphologically similar to the final terminal translocation mode of late-born neurons [7]. To target early-born neurons, IUE experiments were performed at E12.5. Transfected brains were sectioned and examined 5 days later at E17.5. Most neurons in all groups migrated into the CP by E17.5 (Fig. 5C, D), while significantly less occupation of FAK-WT $(n=4)$ and FAK$\mathrm{DN}(\mathrm{n}=4)$ neurons in the upper region of $\mathrm{CP}(\operatorname{Bin} 2-3)$ when compared to $\operatorname{CON}(n=4)$. More neuronal accumulation was observed around the border between the CP and the IZ (Fig. 5D, Bin 10). These observations suggest that FAK deregulation affected the somal translocation of early-born neurons, similar to the phenotype of FAK-WT and FAK-DN at a later stage (electroporation at E14.5).

Collectively, these series of data suggest that FAK is required for the neuronal migration of both early-born and late-born neurons. However, different mechanisms might be involved in these processes.

FAK regulates the phosphorylation of cofilin and the expression of $\mathrm{N}$-Cadherin.

To investigate the molecular mechanisms of how FAK affects neuronal migration, molecules control cytoskeleton dynamics and cellular adhesion, both processes that are highly involved in regulating neuronal migration, were first examined. Previous results showed that Cofilin and N-Cadherin are critical genes in regulating neuronal migration, whose function was closely related to Reelin signaling cascade 
$[18,29,37,38]$. In the present study, FAK phosphorylation at Y925 was found to be highly related to Reelin expression. Therefore, Neuro-2a cells were transfected with FAK-WT and its mutant FAK-DN and then subjected to immunoblot analysis with antibodies against p-cofilin and N-Cadherin (Fig. 6A).

The results showed that the overexpression of FAK-WT did not affect the phosphorylation of cofilin. However, phosphorylation of cofilin was significantly inhibited in cells transfected with FAK-DN (Fig. 6A, B, CON: $1.00 \pm 0.0$, FAK-WT: $0.95 \pm 0.081$, FAK-DN: $0.72 \pm 0.060, F(2,12)=6.451, P=0.012,{ }^{*} p=0.017$, $\left.{ }^{\#} \mathrm{p}=0.049\right)$. In addition, the expression of $\mathrm{N}$-Cadherin was significantly downregulated in the FAK-DN group, while no change was found in cells transfected with FAK-WT (Fig. 6A, B, CON: $1.00 \pm 0.0$, FAK-WT: $1.05 \pm 0.054$, FAK-DN: $\left.0.63 \pm 0.097, F(2,6)=12.26, P=0.008,{ }^{*} p=0.022,{ }^{*} p=0.012\right)$. Given that $p-F A K 925$ was significantly lower in reeler mice (Fig. 1D), we next examined whether cofilin and N-Cadherin expression was affected by reelin knockout. Western blots of $\mathrm{N}$-Cadherin in cortical lysates prepared from P0 wild-type mice $\left(\mathrm{rl}^{+/+}\right)$or their reeler $\left(\mathrm{rl}^{-/-}\right)$littermates showed that the protein level of $\mathrm{N}$-Cadherin was downregulated in reeler mutant mice (Fig. 6C, D, $\mathrm{rl}^{+/+}: 1.00 \pm 0.0, \mathrm{rl}^{-/-}: 0.52 \pm 0.019, \mathrm{p}<0.0001$ ). Phosphorylation of cofilin was lower in reeler as well (Fig. 6C, D, $\mathrm{rl}^{+/+}: 1.00 \pm 0.0, \mathrm{rl}^{-/-}: 0.66 \pm 0.036$, $p<0.0001)$, which confirm previous investigations that Reelin enhances cofilin activity by regulating its phosphorylation [18].

Thus, our observations suggest that the phosphorylation of FAK at Y925 is crucial for different migrating processes via coordinate cytoskeleton dynamics and adhesion, which are highly related to cofilin and NCadherin through the Reelin signaling pathway.

\section{Discussion}

Coordinated corticogenesis during early development has been proposed to underlie precise connectivity and higher brain functions such as learning, memory and cognition (Guy and Staiger, 2017; Kast and Levitt, 2019). Neuronal migration, as a core aspect of corticogenesis, is especially being the interest of research in the last decades. However, until recently, the molecular signaling cascades for controlling neuronal migration during development were not fully uncovered. In the present study, we reported that overexpression of FAK in cortical neurons in vivo disrupts the normal radial migration. This phenotype is likely to be due to inhibited glia-dependent locomotion speed revealed by time-lapse imaging and gliaindependent translocation defects in abundant FAK expression (FAK-WT group) and the absence of FAK Y925 phosphorylation (FAK-DN group). Impaired neuronal migration correlates with actin turnover and focal adhesion site, which appears to be the molecular basis for this phenotype. Indeed, we show that FAK controls actin polymerization and cell adhesion by regulating cofilin phosphorylation and expression of $\mathrm{N}$-Cadherin, respectively. These processes involved phosphorylation of FAK at Y925 and are correlated with Reelin. Our findings reveal a new Reelin regulated mechanism through which FAK controls actin dynamics and cell adhesion, thus neuronal migration during development.

Detailed expression and localization investigation in rat brain revealed ubiquitously presence of FAK in all regions of developing and adult brains, with enrichment in specific neuronal populations of the neocortex, 
hippocampus and cerebellum, particularly during development [39]. In contrast to restricted to focal adhesions in astrocytes, FAK was found in cell bodies, axons, dendrites of neurons and showed no enrichment in any specific neuronal compartment $[39,40]$. In line with this result, FAK-WT and FAK-DN signal was only found in the cytoplasm of either neuronal cell line in vitro or transfected migrating neurons in vivo. Tyrosine phosphorylation is a critical regulator of FAK and is mainly regulated by Src family kinases (SFK) [41]. Although FAK hypophosphorylation was only found in fyn mutants [40], other members of SFK: src and yes were proved to activate FAK in various studies $[42,43,30]$. A wealth of studies documented FAK plays a pivotal role in the regulation of cell proliferation, survival and migration in various cell types [44-49]. Given members of the SFKs have been implicated in neuronal migration, as a downstream kinase that can be phosphorylated by SFK, the function of FAK was investigated during neuronal migration. FAK-null mice showed an embryonic lethal phenotype due to defects in the axial mesodermal tissues and cardiovascular system [32], which limited its use for studies on the roles and mechanisms of FAK in embryonic development. Conditional deletion of FAK in migrating pyramidal neurons did not show any obvious migratory alteration [50], which is conflicting with later researches. Alternatively, in the same year, Xie et al. showed Cdk5 dependent FAK phosphorylation at S732 is critical for the organization of microtubules based nuclear translocation and, in turn, neuronal migration [33]. Conditional ablation and knockdown of FAK showed that FAK is required for radial migration of pyramidal cells, but not for tangential migration of cortical interneurons [34]. In addition, FAK-deficiency induced abundant branching and swelling of the leading process of migrating neurons by a defective assembly of Connexin-26 contact points in the adhesion surface between neurons and radial glial cells. Overexpression of FAK in vivo impaired neuronal migration and layer formation of the neocortex possibly is related to its relationship with vinculin and F-actin cytoskeleton [35]. The involvement of FAK in brain development was also confirmed in another study of Inositol hexakisphosphate kinase 1 (IP6K1) [51]. IP6K1 physiologically interacts with a-actinin and localizes to focal adhesions, whose deletion abolishes FAK autophosphorylation and a-actinin and leads to brain malformation and abnormalities of neuronal migration. The present results add experimental evidence for the involvement of FAK in neuronal migration, during which actin cytoskeleton dynamic and adhesion are both affected by phosphorylation of FAK at Y925. Collectively, increasing evidence showed FAK participate in neuronal migration in a cellautonomous manner.

The results of western blot after FAK overexpression provide first insights into the mechanisms of how FAK is involved in different stages of radial migration. Canonical Reelin signaling involves the very low density lipoprotein receptor (VLDLR) and apolipoprotein E receptor 2 (ApoER2) [52, 27]. The cellular adaptor protein Disabled 1 (Dab1) is phosphorylated by SFK upon binding of Reelin to its receptors, which futher activates SFK and the subsequent downstream molecules [53, 23]. Our observations of colocalization between Reelin and p-FAK and downregulated FAK phosphorylation in reeler mutant experimentally proved the involvement of FAK in the "classical" Reelin signaling pathway to control neuronal migration. Reelin induces cofilin phosphorylation at Serine3, thus stabilizing actin dynamics and controlling the orientation and speed of migrating neurons $[18,29]$. Consistent with these results, cofilin phosphorylation was also significantly reduced in reeler mutants in our observation. Meanwhile, 
dephosphorylation of FAK at Y925 strongly inhibited cofilin phosphorylation, suggesting that FAK regulates neuronal migration through influencing actin cytoskeleton dynamics. This mechanism not only underlies the reduced migrating speed, as well as the final translocation--both processes were disturbed by inhibiting FAK. In contrast to that FAK promotes cancer cell migration thus enhancing invasion [31, 54], we showed overexpressing FAK strongly inhibited neuronal migration in vivo. Although striking similarities in neuronal and cancer cells, there are more contrasts between cancer metastasis and neuronal motility, e.g., migrating substrates, microenvironment, intracellular forces and cytoskeleton arrangement [55]. Neuronal migration is a more intricate process including synergistic cooperation between neurons, glial cells and the extracellular cues. Compared to other phosphorylation sites of FAK, e.g., Y397, Y576/577; S732; Y861 [56], Y925 is of particular especial. Phosphorylated FAK at Y925 creates a specific SH2-binding site for the GRB2 adaptor protein [57]. It has been shown that only FAK Y925 is required for Strain-stimulated AKT phosphorylation for controlling cell migration [58]. Src-dependent phosphorylation of FAK at Y925 specifically promotes detachment of focal adhesions at the trailing edge of migrating neurons [42]. FAK Y 925 phosphorylation is critical for focal adhesions disassembly rate at the cell rear and cell protrusion [47].

In addition, $\mathrm{N}$-Cadherin expression was significantly reduced in reelermice, as well as after FAK dephosphorylation. $\mathrm{N}$-Cadherin is a single-pass transmembrane adhesion receptor required for cell-cell adhesion $[59,60]$. The complex migration mode of late-born neurons involves the glia-neuron adhesion during radial locomotion, indicating the regulatory function of $\mathrm{N}$-Cadherin in neuronal migration. Indeed, $\mathrm{N}$-Cadherin controls neuronal migration and lamination in the neocortex under the control of Reelin transduction [37, 38, 12, 61]. Moreover, knockdown of Myosin X abolishes neuronal N-Cadherin expression and disturbs the adherence of migrating neurons to radial glial cells, resulting in neuronal migration defects [62]. N-Cadherin regulates the migration of late-born neurons by regulating their radial orientation of multipolar stage and asymmetric bridge complex that is required for glial-guided migration $[12,61]$. In our results, dynamics of FAK distribution in different neuronal subregions were observed by time-lapse imaging, suggesting adhesion sites between neurons and other cells are not stabilized during the one locomotion circle, which is consistent with the function of FAK in regulating focal adhesion turnover [47]. Apparently, N-Cadherin stabilizes the leading process in the MZ and facilitates the somal translocation of early-born cortical neurons [37]. In line with these results, glia-independent terminal translocation of late-born neurons was inhibited after FAK overexpression and dephosphorylation. FAK dephosphorylation at Y925 seems strongly inhibit the dynamic transporting of FAK. Reelin transiently enhances the adhesiveness of neurons to $\mathrm{N}$-Cadherin and promotes neuronal aggregation, which is important for correct stopping and positioning of neurons during migration [38]. Unlike this observation, there was no neuronal aggregation observed after manipulating FAK function, suggesting Reelin-FAKmediated $\mathrm{N}$-Cadherin expression might not regulate neuron-neuron adhesion but glia-neuron interaction. It seems that function of $\mathrm{N}$-Cadherin is not only due to its role in mediating cell-cell adhesion, but also cytoskeleton dynamics. Above mentioned function of $\mathrm{N}$-Cadherin in controlling both the radial orientation and translocation involved Rap1 GTPases [37, 61], which provide a key nexus for activating other small 
GTPases, in turn, regulate the actin cytoskeleton [63]. Cadherin can anchor to the actin cytoskeleton, which is a Rac1-regulated process regulating cell polarity, morphology and motility $[64,65]$.

Noncanonical signaling can refer to the involvement of transmembrane proteins other than VLDLR and ApoER2, e.g., integrins. Reelin binds directly to the extracellular domain of integrins and interacts with Dab1 through its NPXY motif in the cytoplasmic tail $[28,13,66]$, thus facilitating cell-cell and cellextracellular matrix (ECM) adhesion [67]. Reelin- $a_{3} \beta_{1}$ integrin interactions inhibit cortical neuronal migration [28] and are required for the formation of the radial glial scaffold necessary for neuronal migration in the hippocampus [20]. As a non-receptor protein tyrosine kinase, FAK is activated by interactions with integrins and functions as a 'scaffold' for the recruitment signaling proteins needed for proliferation [68], extracellular stimulated cell migration [44], neurites outgrowth and axon pathfinding [69, 70]. Moreover, the SH2 binding site for GRB2 at FAK Y 925 partially overlaps with binding sites for paxillin [71], which is an important integrin-binding protein that recruits FAK and vinculin to focal contacts [7274]. Overexpression of a Y925F mutant of FAK resulted in strong focal contact distribution and blocks the turnover of focal contacts $[42,75]$. A point mutation in the Y925 of FAK selectively disrupts GRB2 but promote paxillin binding, then the subsequent association of FAK with $\beta_{1}$-integrin and prevents the dissociation of FAK from focal contacts and leads to inefficient focal turnover [73], which is consistent with our observation of the relatively stable distribution of FAK-DN signal in the migrating neurons. Therefore, although the direct relation between FAK and integrin was not examined in the present study, it strongly suggests that Reelin-integrin-FAK mediated cell-ECM adhesion might be one underlying mechanism for glial-independent translocation. Moreover, the function of FAK in regulating microtubule organization cannot be neglected during the glial-independent translocation process, during which microtubules generate mechanical forces and drive nuclear translocation [76].

In the present study, we show that FAK-mediated Reelin signaling regulates cortical lamination by controlling two key events during embryonic development: glia-dependent locomotion and gliaindependent translocation. Both processes involve dynamic regulating of the actin cytoskeleton and focal adhesions, which might be related to the activity of cofilin and Cadherin. Overall, these data expand the known Reelin signal pathway and provide new insights in understanding neuronal migration mechanisms.

\section{Declarations}

\section{Funding}

This work was supported by the Foundation for top talent recruitment of Xi'an Medical College (No. 2018 RCYJ04 to X.C.), General project of basic research of Shaanxi Province (2020JM-603 to X.C.), National Key Research and Development Program of China (2018YFE0127000 to S.Z.) and German Research Foundation (FR 620/13-1 to M.F.) and the China Scholarship Council to L.S. 


\section{Author contributions}

L.S. M.F. and X.C. designed the experiments, L.S. performed experiments and analyzed the data, X.C. helped with IUE and living imaging, S.Z. discussed the data and contributed to unpublished analytic tools, L.S. interpreted the data and wrote the original draft of the paper. L.S. S.Z. and X.C. discussed and commented on the manuscript.

\section{Acknowledgements}

We are most grateful to Dr. Lei An for helping with the construction of the plasmids. We thank Dr. Joachim Herz for providing reeler mice.

\section{Availability of data and materials}

The data and material supporting the findings of this study are available with the article or is available from the corresponding author upon request.

\section{Code availability}

Not applicable.

\section{Ethics approval}

The animal study was reviewed and approved by the local ethical committee of the University of Hamburg.

\section{Consent for publication}

Not applicable.

\section{Consent to Participate}

Not applicable.

\section{Competing interests}

The authors declare no competing interests.

\section{Compliance with Ethical Standards}




\section{Disclosure of potential conflicts of interest}

Not applicable.

\section{Research involving animals}

The animal study was reviewed and approved by the local ethical committee of the University of Hamburg. Welfare of animals were considered during experiments.

\section{Informed consent}

Not applicable.

\section{References}

1. Guy J, Staiger JF (2017) The Functioning of a Cortex without Layers. Front Neuroanat 11:54

2. Berry M, Rogers AW (1965) The migration of neuroblasts in the developing cerebral cortex.Journal of anatomy99 (Pt 4):691-709

3. Rakic P, Lombroso PJ (1998) Development of the cerebral cortex: I. Forming the cortical structure. J Am Acad Child Adolesc Psychiatry 37(1):116-117

4. Ohtaka-Maruyama C, Okado H (2015) Molecular Pathways Underlying Projection Neuron Production and Migration during Cerebral Cortical Development. Front Neurosci 9:447

5. Noctor SC, Martínez-Cerdeño V, Ivic L, Kriegstein AR (2004) Cortical neurons arise in symmetric and asymmetric division zones and migrate through specific phases. Nat Neurosci 7(2):136-144

6. Hirota Y, Nakajima K (2017) Control of Neuronal Migration and Aggregation by Reelin Signaling in the Developing Cerebral Cortex. Front Cell Dev Biol 5:40

7. Nadarajah B, Brunstrom JE, Grutzendler J, Wong RO, Pearlman AL (2001) Two modes of radial migration in early development of the cerebral cortex. Nat Neurosci 4(2):143-150

8. Nadarajah B, Parnavelas JG (2002) Modes of neuronal migration in the developing cerebral cortex. Nat Rev Neurosci 3(6):423-432

9. Tabata H, Nakajima K (2003) Multipolar Migration: The Third Mode of Radial Neuronal Migration in the Developing Cerebral Cortex. The Journal of Neuroscience 23(31):9996-10001

10. Sekine K, Honda T, Kawauchi T, Kubo K, Nakajima K (2011) The outermost region of the developing cortical plate is crucial for both the switch of the radial migration mode and the Dab1-dependent "inside-out" lamination in the neocortex. J Neurosci 31(25):9426-9439

11. Frotscher M, Zhao S, Wang S, Chai X (2017) Reelin Signaling Inactivates Cofilin to Stabilize the Cytoskeleton of Migrating Cortical Neurons. Front Cell Neurosci 11:148 
12. Horn Z, Behesti H, Hatten ME (2018) N-cadherin provides a cis and trans ligand for astrotactin that functions in glial-guided neuronal migration. Proc Natl Acad Sci U S A 115(42):10556-10563

13. Schmid RS, Maness PF (2008) L1 and NCAM adhesion molecules as signaling coreceptors in neuronal migration and process outgrowth. Curr Opin Neurobiol 18(3):245-250

14. Kubo KI, Deguchi K, Nagai T, Ito Y, Yoshida K, Endo T, Benner S, Shan W, Kitazawa A, Aramaki M, Ishii K, Shin M, Matsunaga Y, Hayashi K, Kakeyama M, Tohyama C, Tanaka KF, Tanaka K, Takashima S, Nakayama M, Itoh M, Hirata Y, Antalffy B, Armstrong DD, Yamada K, Inoue K, Nakajima K (2017) Association of impaired neuronal migration with cognitive deficits in extremely preterm infants.JCl Insight2 (10). doi:10.1172/jci.insight.88609

15. Stouffer MA, Golden JA, Francis F (2016) Neuronal migration disorders: Focus on the cytoskeleton and epilepsy.Neurobiol Dis 92 (Pt A):18-45. doi:10.1016/j.nbd.2015.08.003

16. Subramanian L, Calcagnotto ME, Paredes MF (2019) Cortical Malformations: Lessons in Human Brain Development. Front Cell Neurosci 13:576

17. Gleeson JG, Walsh CA (2000) Neuronal migration disorders: from genetic diseases to developmental mechanisms. Trends Neurosci 23(8):352-359

18. Chai X, Forster E, Zhao S, Bock HH, Frotscher M (2009) Reelin stabilizes the actin cytoskeleton of neuronal processes by inducing n-cofilin phosphorylation at serine3. J Neurosci 29(1):288-299

19. D'Arcangelo G, Miao GG, Chen SC, Soares HD, Morgan JI, Curran T (1995) A protein related to extracellular matrix proteins deleted in the mouse mutant reeler. Nature 374(6524):719-723

20. Förster E, Tielsch A, Saum B, Weiss KH, Johanssen C, Graus-Porta D, Müller U, Frotscher M (2002) Reelin, Disabled 1, and beta 1 integrins are required for the formation of the radial glial scaffold in the hippocampus. Proc Natl Acad Sci U S A 99(20):13178-13183

21. Miyata T, Ono Y, Okamoto M, Masaoka M, Sakakibara A, Kawaguchi A, Hashimoto M, Ogawa M (2010) Migration, early axonogenesis, and Reelin-dependent layer-forming behavior of early/posterior-born Purkinje cells in the developing mouse lateral cerebellum. Neural Dev 5(1):23

22. Beffert U, Weeber EJ, Durudas A, Qiu S, Masiulis I, Sweatt JD, Li WP, Adelmann G, Frotscher M, Hammer RE, Herz J (2005) Modulation of synaptic plasticity and memory by Reelin involves differential splicing of the lipoprotein receptor Apoer2. Neuron 47(4):567-579

23. Howell BW, Herrick TM, Cooper JA (1999) Reelin-induced tyrosine [corrected] phosphorylation of disabled 1 during neuronal positioning. Genes Dev 13(6):643-648

24. Iafrati J, Orejarena MJ, Lassalle O, Bouamrane L, Gonzalez-Campo C, Chavis P (2014) Reelin, an extracellular matrix protein linked to early onset psychiatric diseases, drives postnatal development of the prefrontal cortex via GluN2B-NMDARs and the mTOR pathway. Mol Psychiatry 19(4):417-426

25. Ishii K, Kubo KI, Nakajima K (2016) Reelin and Neuropsychiatric Disorders. Front Cell Neurosci $10: 229$

26. Teixeira CM, Martin ED, Sahun I, Masachs N, Pujadas L, Corvelo A, Bosch C, Rossi D, Martinez A, Maldonado R, Dierssen M, Soriano E (2011) Overexpression of Reelin prevents the manifestation of 
behavioral phenotypes related to schizophrenia and bipolar disorder. Neuropsychopharmacology 36(12):2395-2405

27. Trommsdorff M, Gotthardt M, Hiesberger T, Shelton J, Stockinger W, Nimpf J, Hammer RE, Richardson JA, Herz J (1999) Reeler/Disabled-like disruption of neuronal migration in knockout mice lacking the VLDL receptor and ApoE receptor 2. Cell 97(6):689-701

28. Dulabon L, Olson EC, Taglienti MG, Eisenhuth S, McGrath B, Walsh CA, Kreidberg JA, Anton ES (2000) Reelin binds alpha3beta1 integrin and inhibits neuronal migration. Neuron 27(1):33-44

29. Chai X, Zhao S, Fan L, Zhang W, Lu X, Shao H, Wang S, Song L, Failla AV, Zobiak B, Mannherz HG, Frotscher M (2016) Reelin and cofilin cooperate during the migration of cortical neurons: a quantitative morphological analysis. Development 143(6):1029-1040

30. Wang JT, Song LZ, Li LL, Zhang W, Chai XJ, An L, Chen SL, Frotscher M, Zhao ST (2015) Src controls neuronal migration by regulating the activity of FAK and cofilin. Neuroscience 292:90-100

31. Lim ST, Mikolon D, Stupack DG, Schlaepfer DD (2008) FERM control of FAK function: implications for cancer therapy. Cell cycle (Georgetown, Tex) 7(15):2306-2314

32. Ilić D, Furuta Y, Kanazawa S, Takeda N, Sobue K, Nakatsuji N, Nomura S, Fujimoto J, Okada M, Yamamoto T (1995) Reduced cell motility and enhanced focal adhesion contact formation in cells from FAK-deficient mice. Nature 377(6549):539-544

33. Xie Z, Sanada K, Samuels BA, Shih H, Tsai L-H (2003) Serine 732 Phosphorylation of FAK by Cdk5 Is Important for Microtubule Organization, Nuclear Movement, and Neuronal Migration. Cell 114(4):469-482

34. Valiente M, Ciceri G, Rico B, Marin O (2011) Focal adhesion kinase modulates radial glia-dependent neuronal migration through connexin-26. J Neurosci 31(32):11678-11691

35. An L, Li W, Hu X, Zhang W, Zhao S (2018) Abundant Focal Adhesion Kinase Causes Aberrant Neuronal Migration Via Its Phosphorylation at Y925. J Mol Neurosci 64(1):102-110

36. Saito T, Nakatsuji N (2001) Efficient gene transfer into the embryonic mouse brain using in vivo electroporation. Dev Biol 240(1):237-246

37. Franco SJ, Martinez-Garay I, Gil-Sanz C, Harkins-Perry SR, Muller U (2011) Reelin regulates cadherin function via Dab1/Rap1 to control neuronal migration and lamination in the neocortex. Neuron 69(3):482-497

38. Matsunaga Y, Noda M, Murakawa H, Hayashi K, Nagasaka A, Inoue S, Miyata T, Miura T, Kubo KI, Nakajima K (2017) Reelin transiently promotes N-cadherin-dependent neuronal adhesion during mouse cortical development. Proc Natl Acad Sci U S A 114(8):2048-2053

39. Burgaya F, Menegon A, Menegoz M, Valtorta F, Girault JA (1995) Focal adhesion kinase in rat central nervous system. Eur J Neurosci 7(8):1810-1821

40. Grant SG, Karl KA, Kiebler MA, Kandel ER (1995) Focal adhesion kinase in the brain: novel subcellular localization and specific regulation by Fyn tyrosine kinase in mutant mice. Genes Dev 9(15):19091921 
41. Parsons SJ, Parsons JT (2004) Src family kinases, key regulators of signal transduction. Oncogene 23(48):7906-7909

42. Brunton VG, Avizienyte E, Fincham VJ, Serrels B, Metcalf CA 3, Sawyer TK, Frame MC (2005) Identification of Src-specific phosphorylation site on focal adhesion kinase: dissection of the role of $\mathrm{Src} \mathrm{SH} 2$ and catalytic functions and their consequences for tumor cell behavior. Cancer Res 65(4):1335-1342

43. Chatterji T, Varkaris AS, Parikh NU, Song JH, Cheng CJ, Schweppe RE, Alexander S, Davis JW, Troncoso P, Friedl P, Kuang J, Lin SH, Gallick GE (2015) Yes-mediated phosphorylation of focal adhesion kinase at tyrosine 861 increases metastatic potential of prostate cancer cells. Oncotarget 6(12):10175-10194

44. Sieg DJ, Hauck CR, Schlaepfer DD (1999) Required role of focal adhesion kinase (FAK) for integrinstimulated cell migration.J Cell Sci112 (Pt 16):2677-2691

45. Sonoda Y, Matsumoto Y, Funakoshi M, Yamamoto D, Hanks SK, Kasahara T (2000) Anti-apoptotic role of focal adhesion kinase (FAK). Induction of inhibitor-of-apoptosis proteins and apoptosis suppression by the overexpression of FAK in a human leukemic cell line, HL-60. J Biol Chem 275(21):16309-16315

46. Zhao J, Guan JL (2009) Signal transduction by focal adhesion kinase in cancer. Cancer Metastasis Rev 28(1-2):35-49

47. Deramaudt TB, Dujardin D, Hamadi A, Noulet F, Kolli K, De Mey J, Takeda K, Ronde P (2011) FAK phosphorylation at Tyr-925 regulates cross-talk between focal adhesion turnover and cell protrusion. Mol Biol Cell 22(7):964-975

48. Liu H, Yue J, Huang H, Gou X, Chen SY, Zhao Y, Wu X (2015) Regulation of Focal Adhesion Dynamics and Cell Motility by the EB2 and Hax1 Protein Complex. J Biol Chem 290(52):30771-30782

49. Abbi S, Ueda H, Zheng C, Cooper LA, Zhao J, Christopher R, Guan JL (2002) Regulation of focal adhesion kinase by a novel protein inhibitor FIP200. Mol Biol Cell 13(9):3178-3191

50. Beggs HE, Schahin-Reed D, Zang K, Goebbels S, Nave KA, Gorski J, Jones KR, Sretavan D, Reichardt LF (2003) FAK deficiency in cells contributing to the basal lamina results in cortical abnormalities resembling congenital muscular dystrophies. Neuron 40(3):501-514

51. Fu C, Xu J, Cheng W, Rojas T, Chin AC, Snowman AM, Harraz MM, Snyder SH (2017) Neuronal migration is mediated by inositol hexakisphosphate kinase 1 via alpha-actinin and focal adhesion kinase. Proc Natl Acad Sci U S A 114(8):2036-2041

52. D'Arcangelo G, Homayouni R, Keshvara L, Rice DS, Sheldon M, Curran T (1999) Reelin is a ligand for lipoprotein receptors. Neuron 24(2):471-479

53. Bock HH, Herz J (2003) Reelin activates SRC family tyrosine kinases in neurons. Curr Biol 13(1):1826

54. Schlaepfer DD, Mitra SK, llic D (2004) Control of motile and invasive cell phenotypes by focal adhesion kinase. Biochim Biophys Acta 1692(2-3):77-102 
55. Heine P, Ehrlicher A, Kas J (2015) Neuronal and metastatic cancer cells: Unlike brothers.Biochim Biophys Acta 1853 (11 Pt B):3126-3131. doi:10.1016/j.bbamcr.2015.06.011

56. Mitra SK, Hanson DA, Schlaepfer DD (2005) Focal adhesion kinase: in command and control of cell motility. Nat Rev Mol Cell Biol 6(1):56-68

57. Schlaepfer DD, Hunter T (1996) Evidence for in vivo phosphorylation of the Grb2 SH2-domain binding site on focal adhesion kinase by Src-family protein-tyrosine kinases. Mol Cell Biol 16(10):5623-5633

58. Gayer CP, Chaturvedi LS, Wang S, Alston B, Flanigan TL, Basson MD (2009) Delineating the signals by which repetitive deformation stimulates intestinal epithelial migration across fibronectin. Am $\mathrm{J}$ Physiol Gastrointest Liver Physiol 296(4):G876-G885

59. Fujimori T, Takeichi M (1993) Disruption of epithelial cell-cell adhesion by exogenous expression of a mutated nonfunctional N-cadherin. Mol Biol Cell 4(1):37-47

60. Gumbiner BM (1996) Cell adhesion: the molecular basis of tissue architecture and morphogenesis. Cell 84(3):345-357

61. Jossin Y, Cooper JA (2011) Reelin, Rap1 and N-cadherin orient the migration of multipolar neurons in the developing neocortex. Nat Neurosci 14(6):697-703

62. Lai M, Guo Y, Ma J, Yu H, Zhao D, Fan W, Ju X, Sheikh MA, Malik YS, Xiong W, Guo W, Zhu X (2015) Myosin $\mathrm{X}$ regulates neuronal radial migration through interacting with $\mathrm{N}$-cadherin. Front Cell Neurosci 9:326

63. Park HO, Bi E (2007) Central roles of small GTPases in the development of cell polarity in yeast and beyond. Microbiol Mol Biol Rev 71(1):48-96

64. Gartner A, Fornasiero EF, Dotti CG (2015) Cadherins as regulators of neuronal polarity. Cell Adh Migr $9(3): 175-182$

65. Lambert M, Choquet D, Mege RM (2002) Dynamics of ligand-induced, Rac1-dependent anchoring of cadherins to the actin cytoskeleton. J Cell Biol 157(3):469-479

66. Calderwood DA, Fujioka Y, de Pereda JM, García-Alvarez B, Nakamoto T, Margolis B, McGlade CJ, Liddington RC, Ginsberg MH (2003) Integrin beta cytoplasmic domain interactions with phosphotyrosine-binding domains: a structural prototype for diversity in integrin signaling. Proc Natl Acad Sci U S A 100(5):2272-2277

67. Sekine K, Kawauchi T, Kubo K, Honda T, Herz J, Hattori M, Kinashi T, Nakajima K (2012) Reelin controls neuronal positioning by promoting cell-matrix adhesion via inside-out activation of integrin alpha5beta1. Neuron 76(2):353-369

68. Shibue T, Weinberg RA (2009) Integrin beta1-focal adhesion kinase signaling directs the proliferation of metastatic cancer cells disseminated in the lungs. Proc Natl Acad Sci U S A 106(25):1029010295

69. Ivankovic-Dikic I, Gronroos E, Blaukat A, Barth BU, Dikic I (2000) Pyk2 and FAK regulate neurite outgrowth induced by growth factors and integrins. Nat Cell Biol 2(9):574-581 
70. Robles E, Gomez TM (2006) Focal adhesion kinase signaling at sites of integrin-mediated adhesion controls axon pathfinding. Nat Neurosci 9(10):1274-1283

71. Liu G, Guibao CD, Zheng J (2002) Structural insight into the mechanisms of targeting and signaling of focal adhesion kinase. Mol Cell Biol 22(8):2751-2760

72. Brown MC, Perrotta JA, Turner CE (1996) Identification of LIM3 as the principal determinant of paxillin focal adhesion localization and characterization of a novel motif on paxillin directing vinculin and focal adhesion kinase binding. J Cell Biol 135(4):1109-1123

73. Klingbeil CK, Hauck CR, Hsia DA, Jones KC, Reider SR, Schlaepfer DD (2001) Targeting Pyk2 to beta 1-integrin-containing focal contacts rescues fibronectin-stimulated signaling and haptotactic motility defects of focal adhesion kinase-null cells. J Cell Biol 152(1):97-110

74. Liu S, Thomas SM, Woodside DG, Rose DM, Kiosses WB, Pfaff M, Ginsberg MH (1999) Binding of paxillin to alpha4 integrins modifies integrin-dependent biological responses. Nature 402(6762):676-681

75. Katz BZ, Romer L, Miyamoto S, Volberg T, Matsumoto K, Cukierman E, Geiger B, Yamada KM (2003) Targeting membrane-localized focal adhesion kinase to focal adhesions: roles of tyrosine phosphorylation and SRC family kinases. J Biol Chem 278(31):29115-29120

76. Nakazawa N, Kengaku M (2020) Mechanical Regulation of Nuclear Translocation in Migratory Neurons. Front Cell Dev Biol 8:150

\section{Figures}




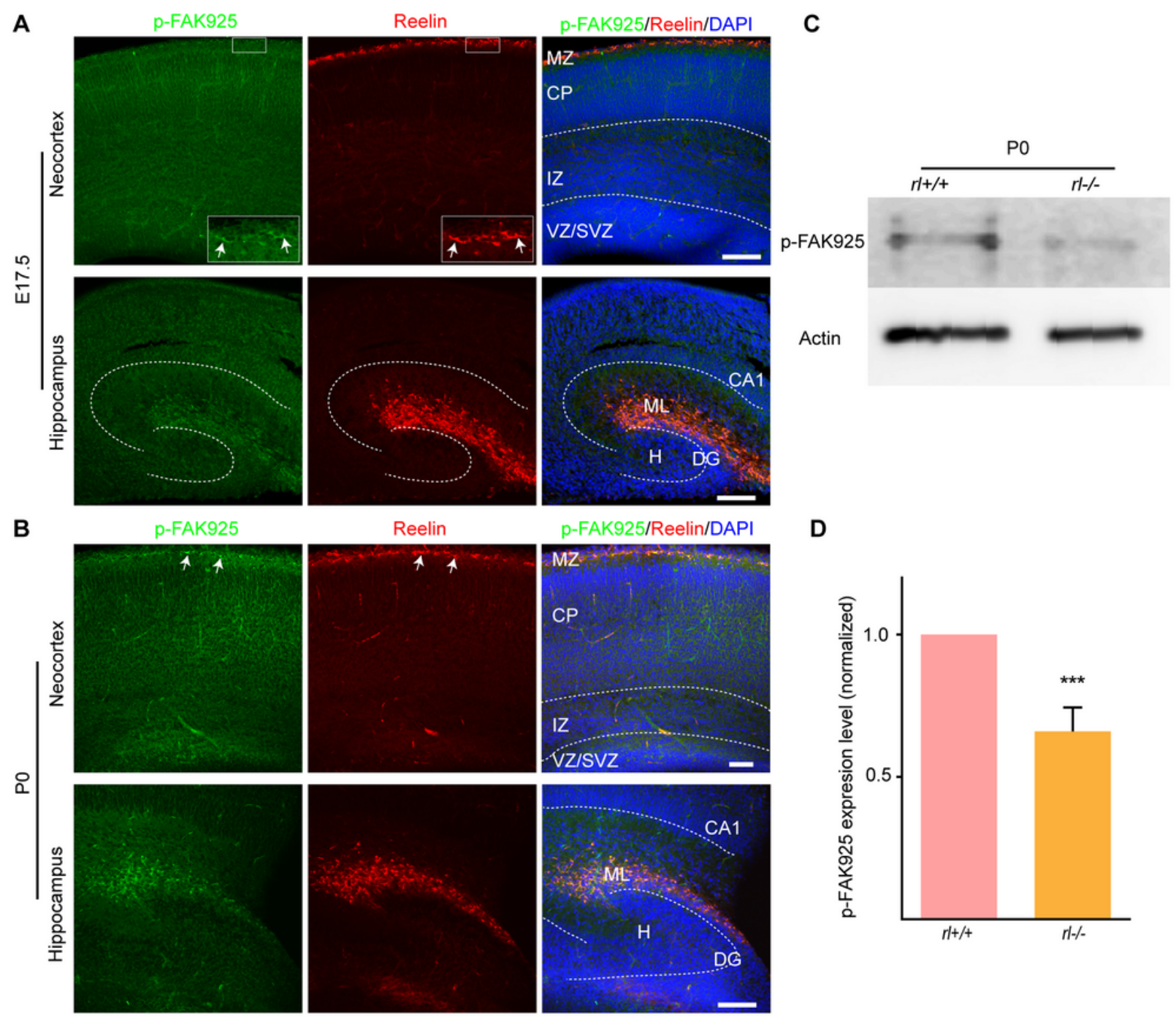

Figure 1 -Song et al.

\section{Figure 1}

p-FAK925 was highly expressed in Reelin-positive Cajal-Retzius cells in the marginal zone of developing neocortex and hippocampus. A, Representative fluorescent images of phosphorylated focal adhesion kinase (p-FAK925, green) in neocortex (up row) and hippocampus (bottom row) slices from E17.5 mice when co-stained with Reelin (red) and DAPI (blue). Insets, colocalization of p-FAK and Reelin (arrows) shown at higher magnification. Dotted lines mark area borders. Scale bar, $100 \mu \mathrm{m}$. MZ: marginal zone, CP: cortical plate, IZ: intermediate zone, VZ: ventricular zone, CA1: Cornu Ammonis 1, DG: dentate gyrus, H: hilus, ML: molecular layer. B, Same as A, for P0 mice. Scale bar, $50 \mu \mathrm{m}$. C, Western blotting for $\mathrm{p}$ FAK925 expression in cortical lysates from P0 wild-type mice (rl+/+) or their reeler (rl-/-) littermates. Actin 
was used as a loading control. D, Densitometric analysis of relative p-FAK925 expression level from three independent experiments. Data are presented as mean \pm SEM. Student's t-test, ${ }^{\star \star \star} p<0.001$.

A

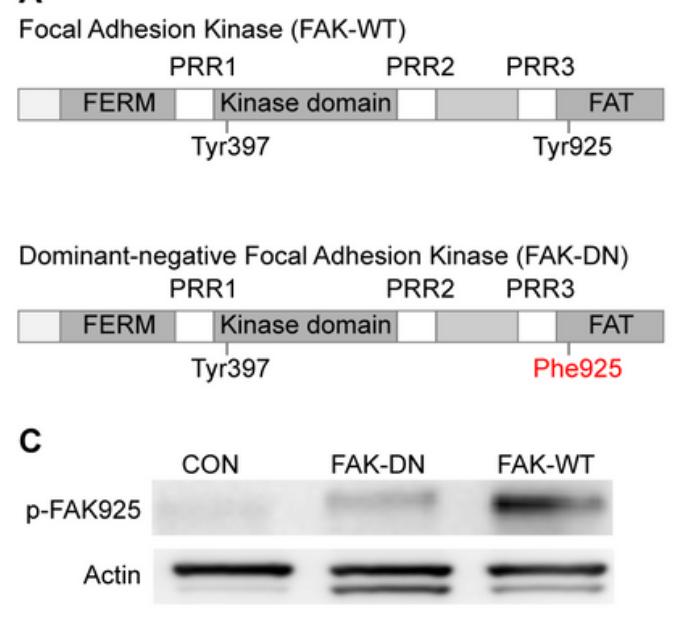

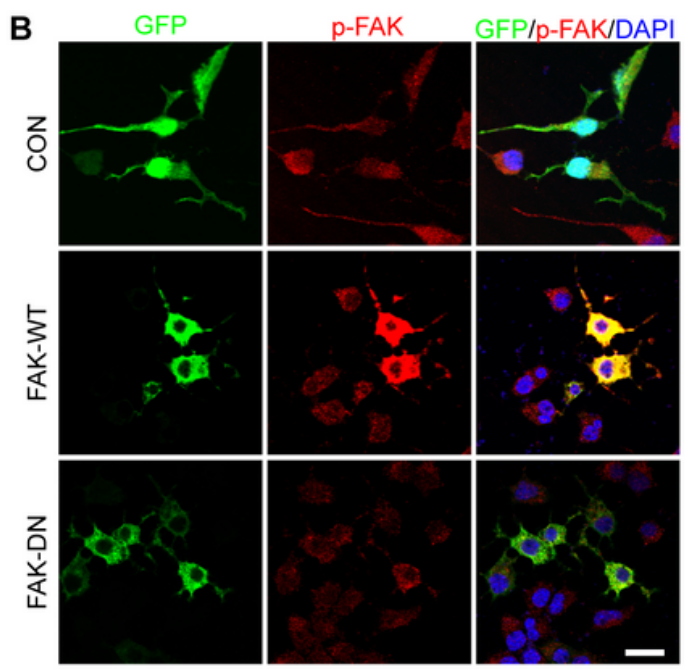

Figure 2 -Song et al.

\section{Figure 2}

Construction and verification of wild-type and dominant-negative FAK plasmids. A, Schematic diagrams of FAK function motifs and the mutated amino acid (Phe925). All constructs express a fusion protein of FAK or its mutants and GFP. B, Representative images of neuro-2a cells after 24h transfection with different constructs. GFP (green) expression was detected in the whole cells transfected with control plasmid expressing GFP (up row), while only in the cytoplasm of cells transfected with plasmids expressing FAK-WT (middle row) and FAK-DN (bottom row). Cells were co-stained with p-FAK (red) and DAPI (blue). Scale bar, $20 \mu \mathrm{m}$. C, Western blotting p-FAK925 expression from neuro-2a cells after $48 \mathrm{~h}$ transfection with different constructs. Actin (upper band) was used as a loading control. 
A
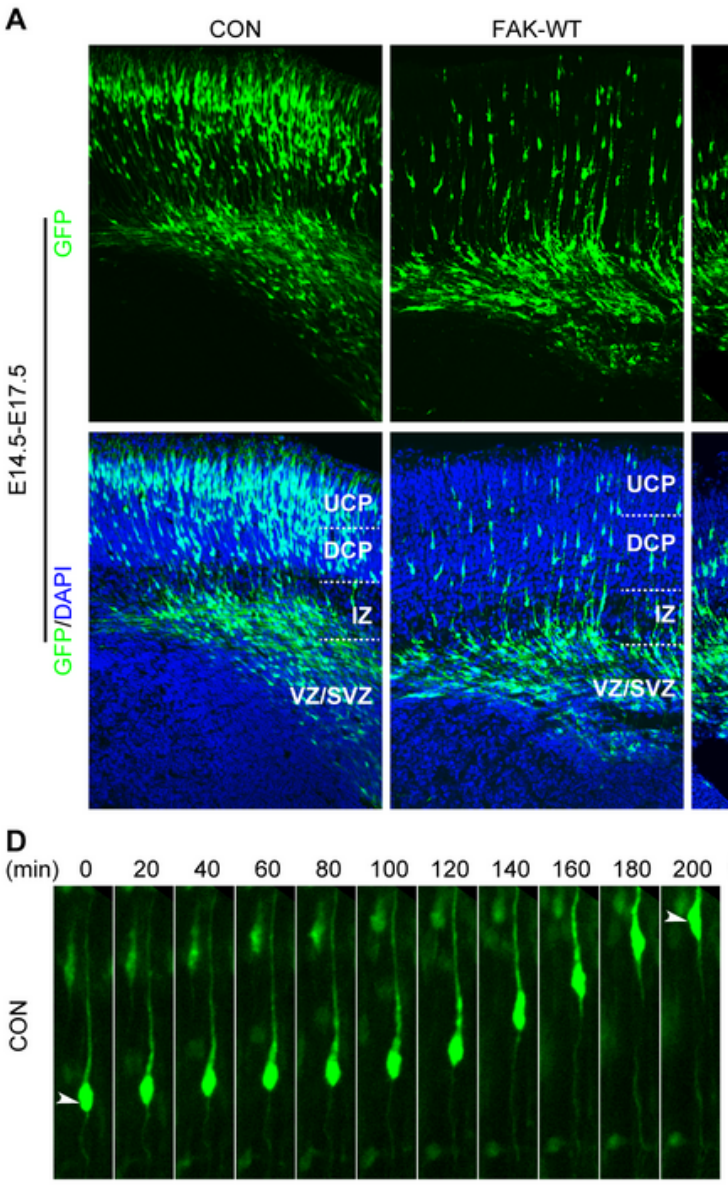

D

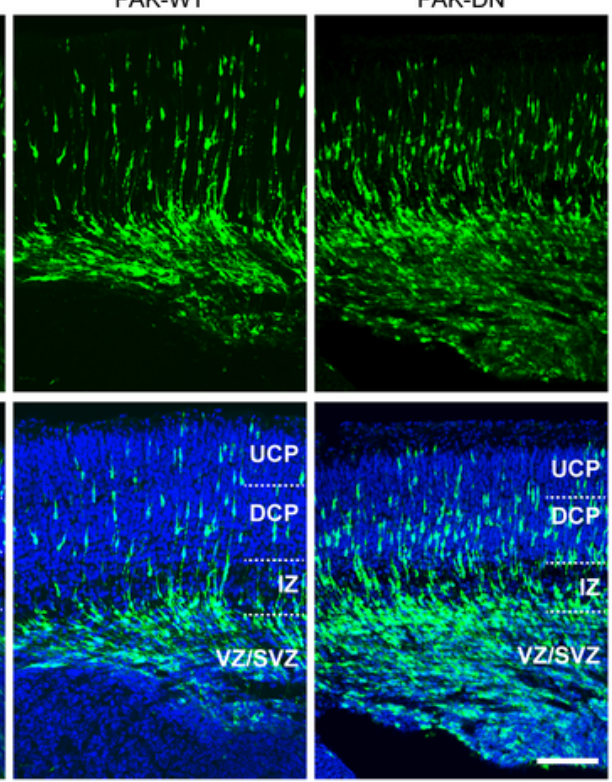

FAK-WT

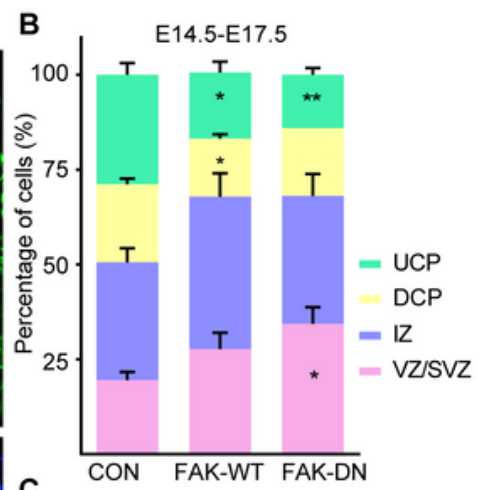

C

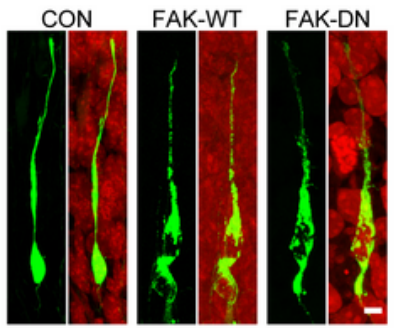

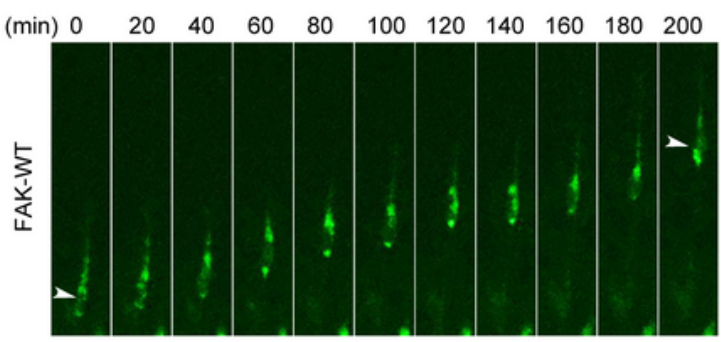

$\mathrm{E}$
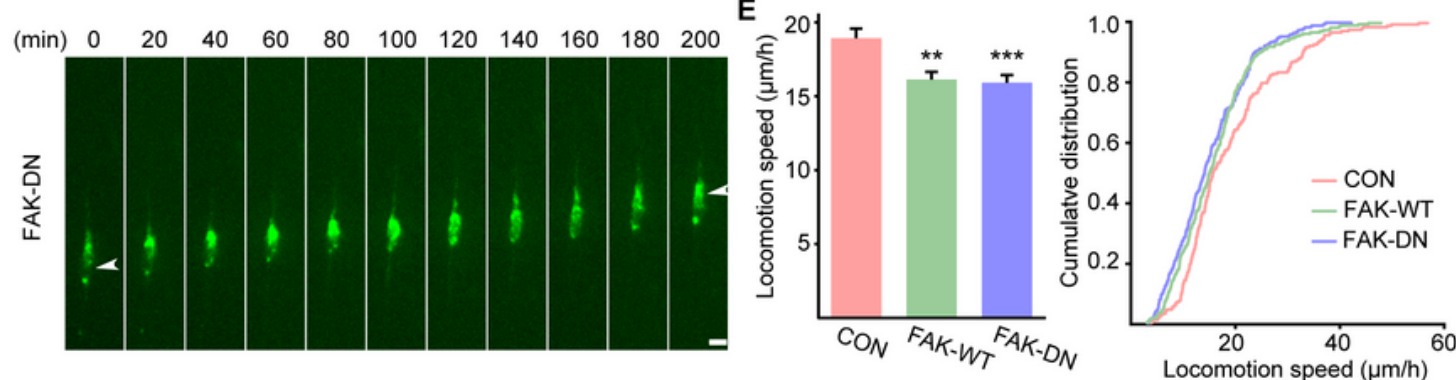

Figure 3 -Song et al.

\section{Figure 3}

Overexpression of FAK-WT and FAK-DN disrupted the migration of late-born neurons in the neocortex. A, Representative images showing the distribution of late-born cortical neurons (green) in DAPI (blue) stained coronal slices from E17.5 mice electroporated with CON (left), FAK-WT (middle), FAK-DN (right) at E14.5. Scale bar, $100 \mu \mathrm{m}$. B, Quantitative analysis of the distribution pattern of electroporated cortical neurons across four different cortical zones at E17.5. C, Higher magnifications of migrating neurons in 
CP of E17.5 cortical sections electroporated at E14.5. Sections were counter stained with DAPI (red). Scale bar, $10 \mu \mathrm{m}$. D, Migratory behavior of neurons transfected with the different constructs 3 days after IUE. Individual neurons were monitored over a period of $200 \mathrm{~min}$ (selected neurons from Movies 1-7). White arrowheads indicate the somata. Scale bar, $10 \mu \mathrm{m}$. E, Quantitative assessment (left) and cumulative distribution (right) of locomotion speed of migrating neurons 3 days after IUE. Data are presented as mean \pm SEM. One-way ANOVA test followed by Bonferroni-corrected post hoc test, ${ }^{*} p<0.05$, ${ }^{* \star} \mathrm{p}<0.01, * \star * \mathrm{p}<0.001$

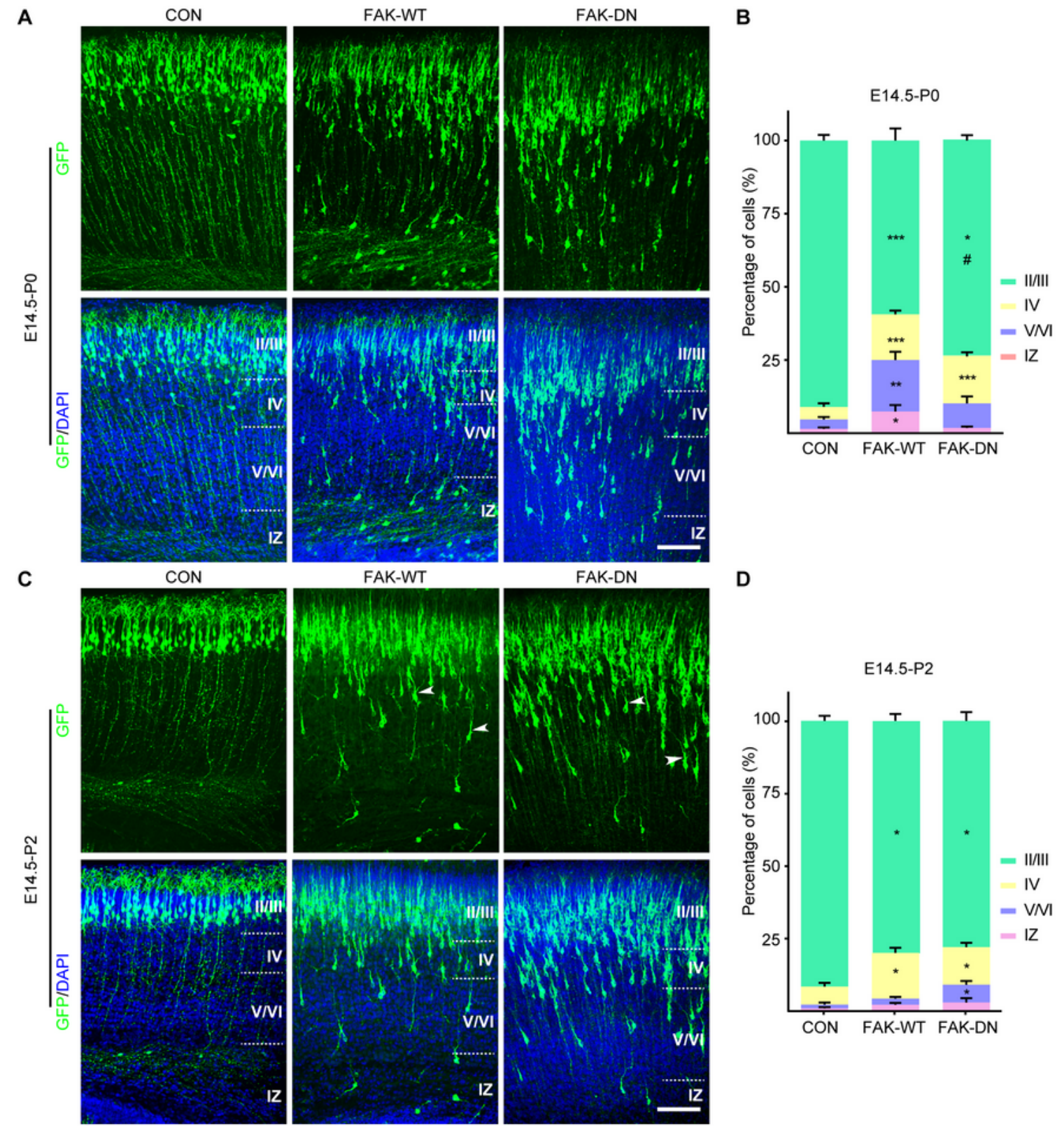

Figure 4 -Song et al. 


\section{Figure 4}

Late-born neurons transfected with FAK-WT and FAK-DN were unable to reach their final destination.

Retarded and inhibited neuronal migration of late-born neurons after transfection of FAK-WT and FAK-DN. A, Representative images showing the distribution of the transfected late-born cortical neurons (green) from P0 mice electroporated with CON (left), FAK-WT (middle), FAK-DN (right) at E14.5. The sections were counterstained with DAPI (blue). Scale bar, $100 \mu \mathrm{m}$. B, Quantitative analysis of the distribution pattern of electroporated cortical neurons across four different cortical zones at P0. C-D, Same as A-B, for P2 mice. White arrowheads in $\mathrm{C}$ indicate neurons with multiple branches. Scale bar, $100 \mu \mathrm{m}$. Data are presented as mean \pm SEM. One-way ANOVA test followed by Bonferroni-corrected post hoc test, ${ }^{*}, \# p<0.05,{ }^{*} p<0.01$, $\star \star \star p<0.001$. 

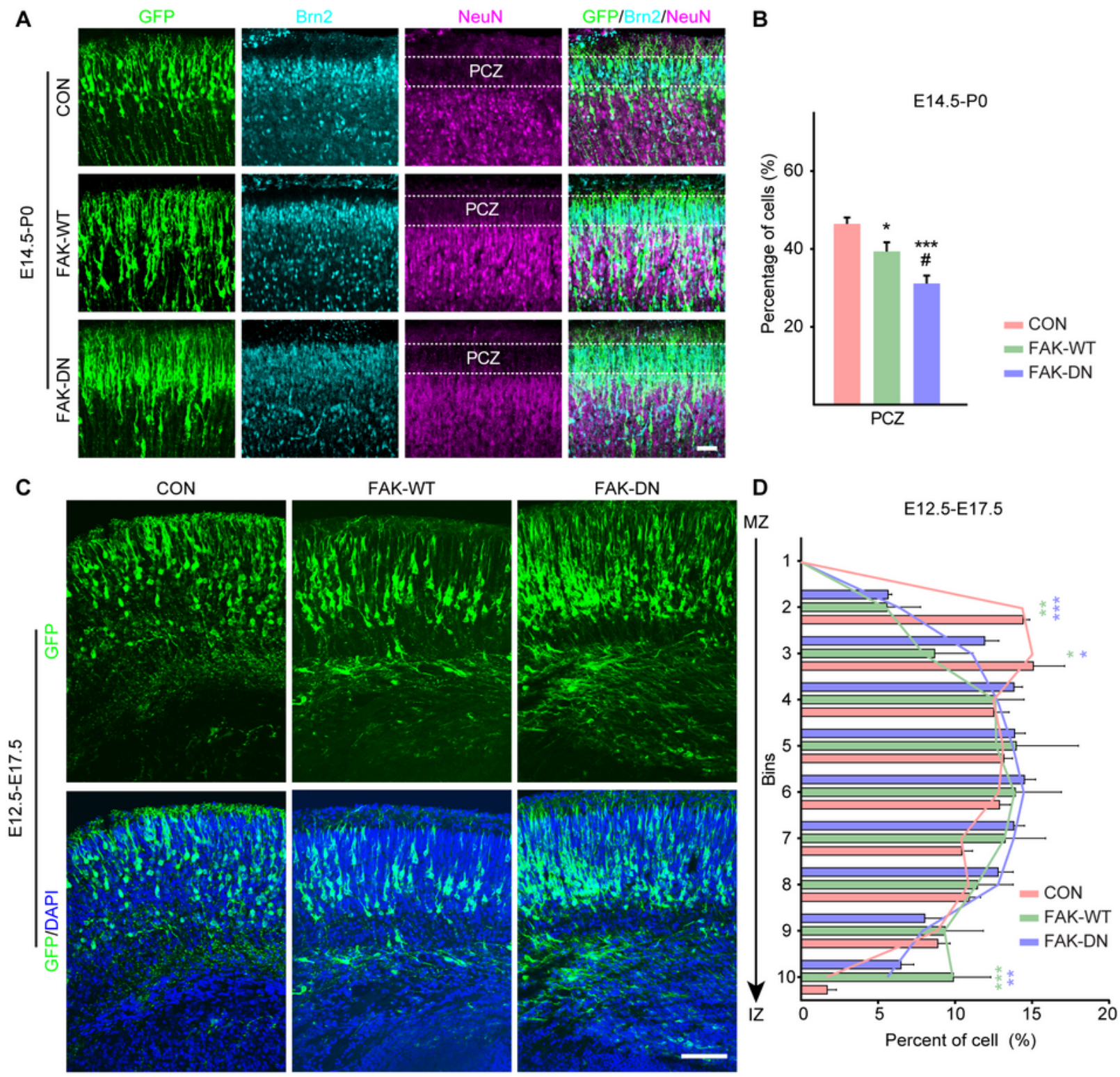

Figure 5 -Song et al.

\section{Figure 5}

Overexpression of FAK-WT and FAK-DN disrupted the translocation of late-born and early-born neurons in the neocortex. A, Representative images showing the soma location of transfected late-born cortical neurons (green) in upper layers of coronal slices from P0 mice electroporated with CON (left), FAK-WT (middle), FAK-DN (right) at E14.5. Brn2 (cyan) and NeuN (Magenta) were used to identify the primitive cortical zone (PCZ) (Brn2+NeuN-). Scale bar, $100 \mu \mathrm{m}$. B, Quantitative analysis of the percentage of 
electroporated cortical neurons in PCZ at P0. C, Representative images showing the distribution of the transfected early-born cortical neurons (green) in neocortex from E17.5 mice electroporated with CON (left), FAK-WT (middle), FAK-DN (right) at E12.5. The sections were counterstained with DAPI (blue). Scale bar, $100 \mu \mathrm{m}$. D, Bin analysis of the distribution pattern of electroporated cortical neurons across cortex at E17.5. The area from the outer margin of the CP to the inner margin of the VZ was divided into 10 equally spaced bins and the transfected neurons in each bin were counted. Data are presented as mean \pm SEM. One-way ANOVA test followed by Bonferroni-corrected post hoc test, ${ }^{*}, \# p<0.05,{ }^{*} \mathrm{p}<0.01,{ }^{\star \star \star} \mathrm{p}<0.001$.

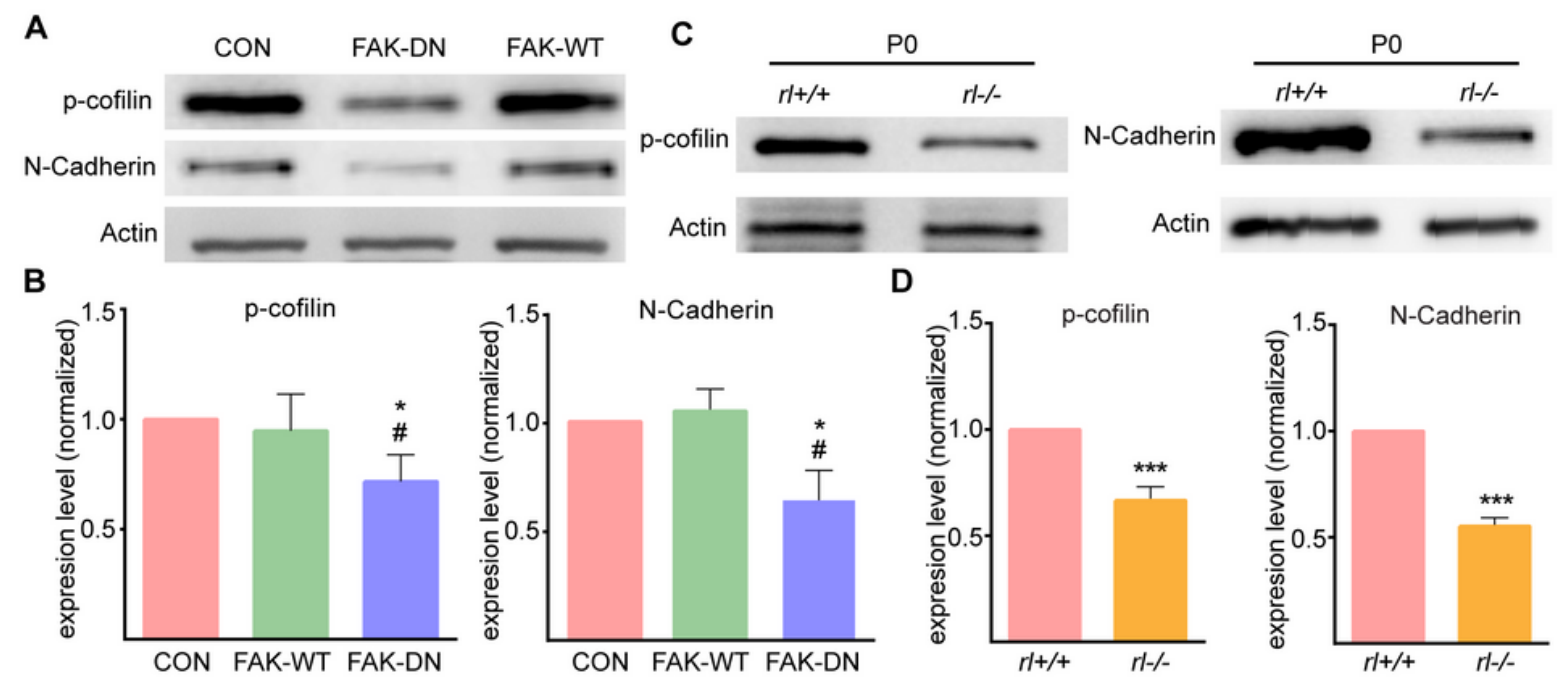

Figure 6 -Song et al.

\section{Figure 6}

Reelin and FAK regulate cofilin phosphorylation and $\mathrm{N}$-Cadherin expression. $\mathrm{A}$, Western blotting for $\mathrm{p}$ cofilin and $\mathrm{N}$-Cadherin expression from neuro-2a cells after $48 \mathrm{~h}$ transfection with different constructs. Actin was used as a loading control. B, Densitometric analysis of relative $\mathrm{p}$-cofilin and $\mathrm{N}$-Cadherin expression level from three independent experiments (t-tests, $\left.{ }^{\star \star *} p<0.001\right)$. C, Western blotting for $p$ cofilin and $\mathrm{N}$-Cadherin expression in cortical lysates from P0 wild-type mice $(\mathrm{rl}+/+)$ or their reeler $(\mathrm{rl}-/-)$ littermates. Actin was used as a loading control. D, Densitometric analysis of relative p-cofilin and NCadherin expression level from three independent experiments. Data are presented as mean \pm SEM. Student's t-test, ${ }^{\star \star *} \mathrm{p}<0.001$.

\section{Supplementary Files}


This is a list of supplementary files associated with this preprint. Click to download.

- Movie1CON.avi

- Movie2CONcotransfectedwithRFP.avi

- Movie3FAKWT.avi

- Movie4FAKWTcotransfectedwithRFP.avi

- Movie5FAKDN.avi

- Movie6FAKDNcontransfectedwithRFP.avi

- Movie7FAKDNhigherexpression.avi 